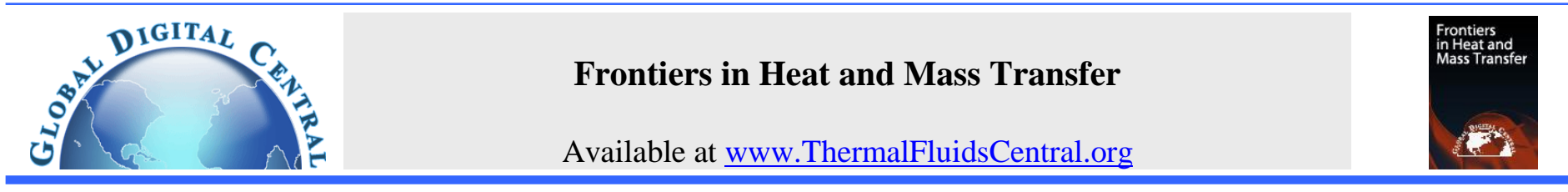

\title{
CONVECTIVE HEAT TRANSFER, FRICTION FACTOR AND THERMAL PERFORMANCE IN A ROUND TUBE EQUIPPED WITH THE MODIFIED V-SHAPED BAFFLE
}

\author{
Amnart Boonloi ${ }^{\mathrm{a}}$ and Withada Jedsadaratanachai ${ }^{\mathrm{b}, *}$ \\ ${ }^{a}$ Department of Mechanical Engineering Technology, College of Industrial Technology, King Mongkut's University of Technology North Bangkok, \\ Bangkok 10800, Thailand \\ ${ }^{b}$ Department of Mechanical Engineering, Faculty of Engineering, King Mongkut's Institute of Technology Ladkrabang, Bangkok 10520, Thailand
}

\begin{abstract}
Convective heat transfer, pressure loss and thermal performance in a heat exchanger tube inserted with the modified V-shaped baffle are investigated numerically. The influences of the flow attack angle $\left(\alpha=20^{\circ}, 30^{\circ}\right.$ and $\left.45^{\circ}\right)$, baffle height in term of blockage ratio $(\mathrm{b} / \mathrm{D}=\mathrm{BR}=0.05,0.10,0.15,0.20$ and 0.25 ) and arrangement (The V-tip pointing downstream is called "V-Downstream", while the V-tip pointing upstream is named "V-Upstream".) on heat transfer and friction loss are presented for the Reynolds number in range $100-1200$ (laminar region). The numerical study (finite volume method) is selected to solve the current investigation and to describe the mechanisms inside the heat exchanger tube. The flow visualizations and heat transfer characteristics in the heat exchanger tube are plotted in the numerical-result report. The results on heat transfer, friction factor and thermohydraulic performance of the test tube are compared with the smooth circular tube. It is found that the vortex strength in the heat exchanger tube is an important factor to enhance heat transfer rate and thermal performance. In addition, the maximum thermal enhancement factor is around 3.22 at $\alpha=$ $30^{\circ}, \mathrm{BR}=0.2, \mathrm{Re}=1200$ for V-Upstream arrangement.
\end{abstract}

Keywords: convective heat transfer; thermal performance; heat exchanger tube; flow visualization; baffle.

\section{INTRODUCTION}

The effort to improve the heat transfer rate and thermal performance in various heat exchangers had been seen in many industries. The improvement method can divide into two techniques; active and passive techniques. The active technique needs the additional power for the heating system to enhance heat transfer rate and thermal performance. The passive technique is the addition of the vortex generator in the heating system to create the vortex flow, which enhances heat transfer rate. The selection of the vortex generator depends on the application of the heat exchanger. Many researchers had been studied the insertions of the vortex generator to augment heat transfer rate and thermal performance. Almost researchers believes that the understanding on flow and heat transfer mechanisms is an important point to improve heat transfer rate and thermal performance of the heat exchanger and to help to design the compact heat exchanger.

The V-shaped baffle/rib is a type of the vortex generator, which always insert in the tube/channel heat exchanger to produce vortex flow. The V-shaped baffle gives high effectiveness to augment heat transfer and thermal performance in comparison with other types of the vortex generator. For examples, Jin et al. (2017) numerically studied flow and heat transfer behavior in a solar air heater system with staggered multiple $\mathrm{V}$-shaped ribs on the absorber plate. The influences of rib height, pitch, attack angle and Reynolds number were considered. They reported that the staggered multiple V-shaped ribs give higher heat transfer rate and thermohydraulic performance factor than the

Corresponding author.Email: kjwithad@kmitl.ac.th inline arrangement around $26 \%$ and $18 \%$, respectively. Deo et al. (2016) examined the heat transfer rate and flow structure in a rectangular duct placed on one side with multi-gap V-down ribs combined with staggered ribs for $\mathrm{Re}=4000-12,000$. The rib pitch-toheight, rib height-to-hydraulic diameter and flow attack angle were varied. They concluded that the heat transfer rate and thermohydraulic performance are around 3.34 and 2.45 times above the base case, respectively. Fang et al. (2015) investigated turbulent flow in a square channel with various flow attack angles $\left(30^{\circ}, 45^{\circ}\right.$ and $\left.60^{\circ}\right)$ of $\mathrm{V}$-shaped ribs placed on one wall. Kumar and Kim (2015) reported the effects the roughness width ratios in discrete multi V-rib with staggered rib roughness on overall thermal performance for a solar air heater channel. They found that the relative width ratio of 6 performs the highest Nusselt number, while the relative width ratio of 1 gives the reverse result. They also summarized that the overall thermal performance of discrete multi V-rib with staggered rib shape is around $6 \%$ higher as compared to other rib shapes. Singh and Ekkad (2017) experimentally studied the heat transfer augmentation in a two pass channel fitted with $\mathrm{V}$-shaped ribs and cylindrical dimples for $\mathrm{Re}=19,500-69,000$. They claimed that the combination of ribs and dimples provides greater heat transfer rate and thermal performance than the ribs alone and dimple alone. Maithani and Saini (2016) presented the experimental investigations on heat transfer and friction loss in a solar air heater duct fitted with V-ribs with symmetrical gaps. The influences of the number of gaps, relative gap width, relative roughness pitch, angle of attack on heat transfer and flow mechanisms were studied for $\mathrm{Re}=4000-$ 18,000. They detected that the heat transfer rate and friction loss are around 3.6 and 3.67 times higher than the smooth duct. Kumar and Kim (2016) reported the numerical investigations on fluid flow and heat 
transfer characteristics in an air duct with various $\mathrm{V}$-pattern rib roughnesses on the heated plate. They showed that the V-rib with a combination of groove performs greater thermal performance than other comparable V-pattern rib roughness shapes. Promthaisong et al. (2016) numerically investigated convective heat transfer, friction factor and thermal performance in a square channel fitted with discrete broken Vribs. The effects of the open corner ratios on flow and heat transfer mechanisms were considered. They concluded that the reduction of the open corner ratio leads to an increase in heat transfer rate and friction factor. Jin et al. (2015) numerically studied the flow structure and heat transfer in a solar air heater duct with multi $\mathrm{V}$-shaped ribs on the absorber plate. They detected that the optimum thermal performance is around 1.93. Abraham and Vedula (2016) examined the heat transfer rate and pressure loss in a square cross-section converging channel fitted with $\mathrm{V}$ and $\mathrm{W}$ ribs for $\mathrm{Re}=5000-35,000$. Karwa and Chitoshiya (2013) studied the influences of the $60^{\circ} \mathrm{V}$-down discrete ribs on the absorber plate in a solar air heater channel. They stated that the augmentation on the thermal performance is around $12.5-20 \%$ depended on the flow rate. Singh et al. (2012) presented the influences of the flow attack angle $\left(30^{\circ}-75^{\circ}\right)$ for the V-down rib with gap in a rectangular duct on heat transfer and thermal performance. They summarized that the highest heat transfer rate, friction loss and thermohydraulic performance are detected at the flow attack angle of $60^{\circ}$. Ravi and Saini (2016) studied thermal performance of a double pass solar air heater duct having roughness elements of the combination of discrete multi V-shaped and staggered ribs. They reported that the addition of the ribs not enhances only heat transfer rate, but also increases the pressure loss. Promvonge et al. (2011) numerically investigated turbulent flow and heat transfer in a square duct fitted with inline $60^{\circ}$ $\mathrm{V}$-shaped discrete ribs. They found that the best thermal enhancement factor is around 1.8 at the rib height-to-hydraulic diameter of 0.0725 . Hans et al. (2010) reported the correlations of heat transfer and friction factor for a solar air heater duct placed with multiple $\mathrm{V}$-ribs in the range $\operatorname{Re}=2000-12,000$. The relative roughness height, relative roughness pitch, flow attack angle and relative roughness width were considered. The influences of rib height on local heat transfer distribution and pressure loss in a square channel with $90^{\circ}$ continuous and $60^{\circ} \mathrm{V}$-broken ribs were studied by SriHarsha et al. (2009). They concluded that the $60^{\circ} \mathrm{V}$-broken ribs performs higher heat transfer rate than the $90^{\circ}$ continuous rib and also gives lower pressure loss. Lee et al. (2009) compared the $60^{\circ}$ continuous V-rib and $45^{\circ}$ multiple (staggered) V-rib in various aspect ratios of the rectangular channel on heat and mass transfer. They found that the variation of the aspect ratio has effect for the $60^{\circ}$ continuous $\mathrm{V}$-rib more than the $45^{\circ}$ multiple (staggered) V-ribs. The thermal improvement in a solar air heater duct with $\mathrm{V}$-shaped rib with gap was reported by Kumar et al. (2013). The influences of the Reynolds number, relative gap distance, relative gap width, relative roughness height, relative roughness pitch, relative roughness width ratio and flow attack angle on heat transfer, pressure loss and thermal performance were considered. They found that the maximum Nusselt number and friction factor are around 6.74 and 6.37 times above the smooth duct, respectively. Singh et al. (2011) claimed that the maximum augmentations on Nusselt number and friction factor are around 3.04 and 3.11 times over the smooth duct, respectively, when inserted the discrete $\mathrm{V}$-down ribs in a solar air heater duct in the range investigation; $\operatorname{Re}=3000-15,000$, relative gap width of $0.5-2.0$, relative gap position of $0.2-0.8$, relative roughness pitch of $4-12$, angle of attack of $30^{\circ}-75^{\circ}$ and relative roughness height $0.015-0.043$. Caliskan and Baskaya (2012) studied the velocity profile and turbulence effects on heat transfer behaviors for V-ribs surface. Karwa and Chauhan (2010) studied thermo-hydraulic performance improvement in a solar air heater duct with $60^{\circ} \mathrm{V}$-down discrete rib on the absorber plate. Kumar et al. (2012) experimentally investigated the heat transfer rate and flow structure in a rectangular duct with multi $\mathrm{V}$-shaped rib with gap on the heated plate. The relative gap distance and relative gap width were considered for $\operatorname{Re}=2000-20,000$. They found that the relative gap distance of 0.69 with relative gap width of 1 provides the best thermal performance.

As the literature reviews above and our previous works, it can conclude that the $\mathrm{V}$-shaped baffle gives high effectiveness to enhance heat transfer rate and thermal performance when compared with other generators. However, it is difficult to install the $\mathrm{V}$-shaped baffle in the heat exchanger tube. Therefore, the $\mathrm{V}$-shaped baffle is modified to increase the stability for the installation in the round tube heat exchanger. The influences of the Reynolds number, flow attack angle, baffle height and baffle arrangement on heat transfer, pressure loss and thermal performance are considered. The mechanisms on flow and heat transfer in the heat exchanger tube equipped with the modified Vshaped baffle are reported.

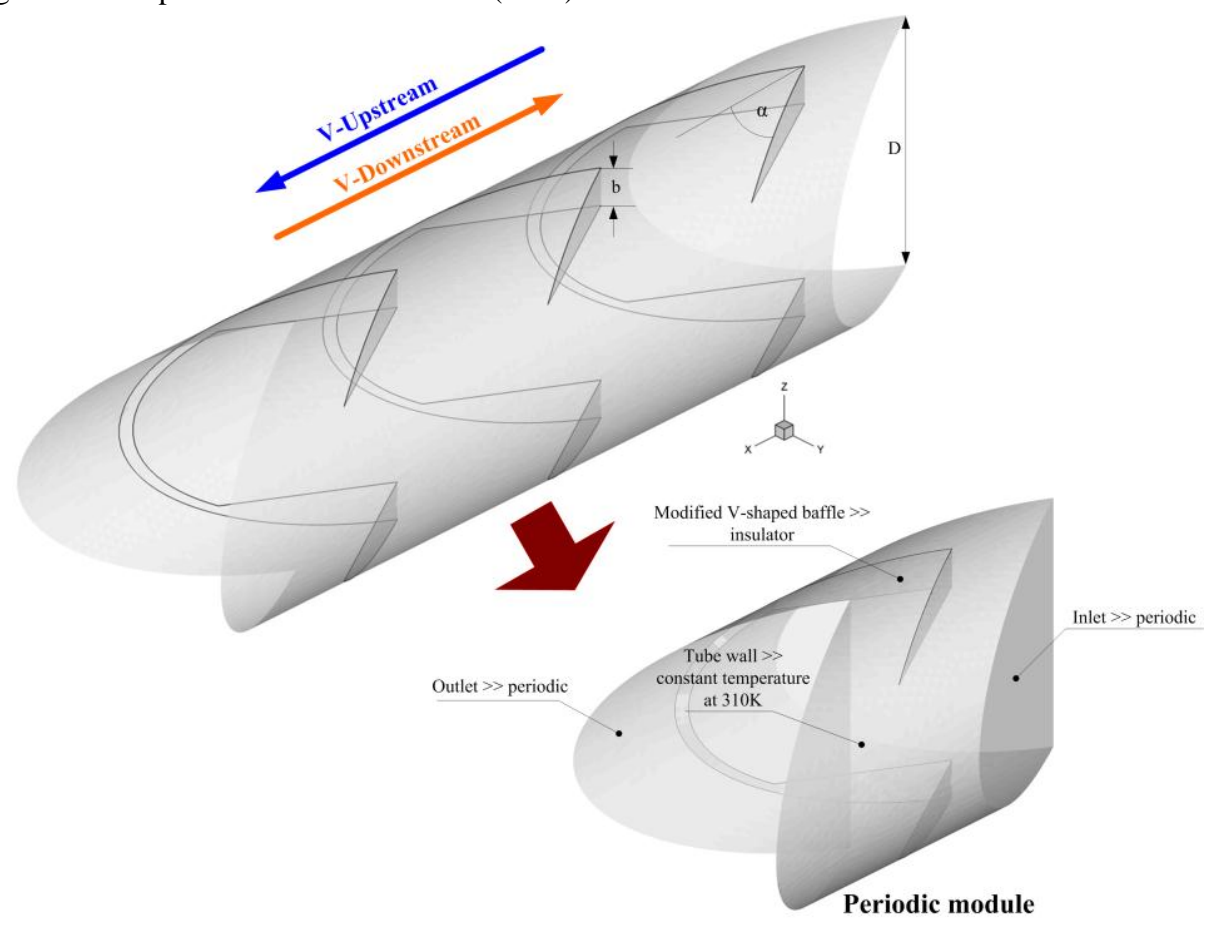

Fig. 1 Physical domain of the heat exchanger tube equipped with modified V-shaped baffle. 


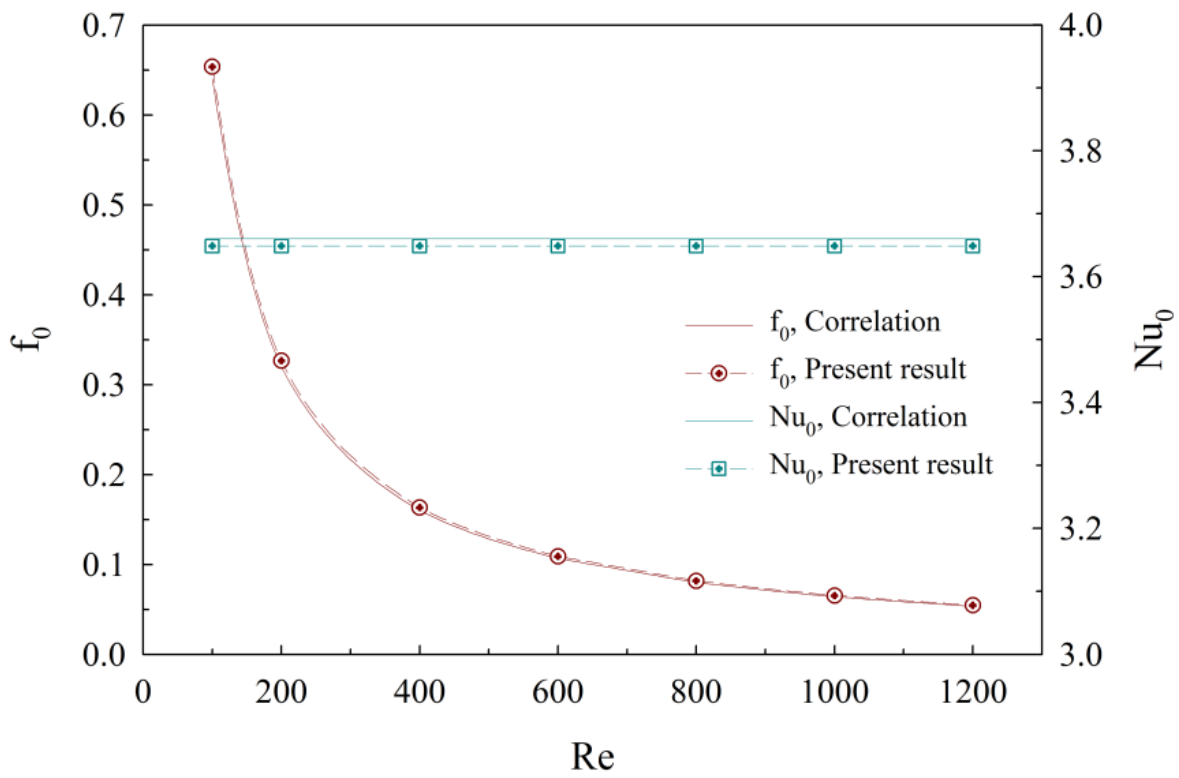

Fig. 2 Validation of the smooth circular tube.

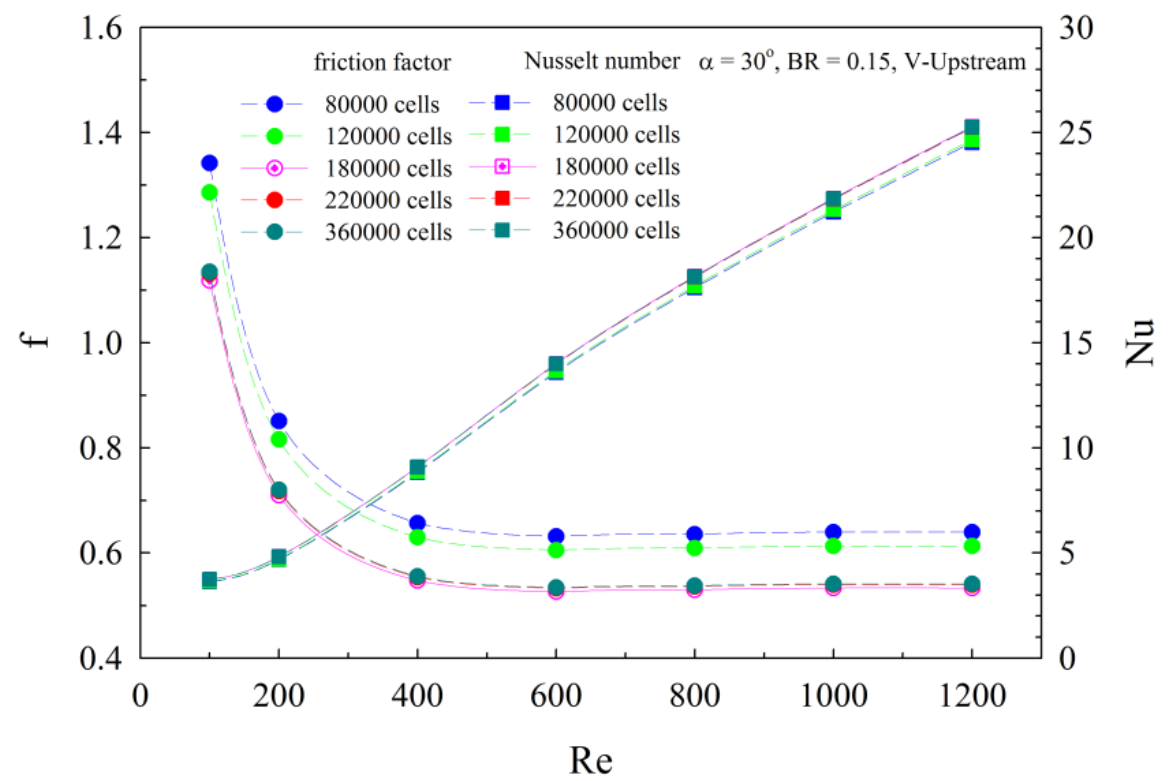

Fig. 3 Grid independence.

\section{PHYSICAL GEOMETRY AND MODIFIED V- SHAPED ARRANGEMENT}

The physical geometry of the heat exchanger tube equipped with the modified V-shaped baffle is presented as Fig. 1. The modified Vshaped baffles are inserted in the round tube on both $\mathrm{V}$-Downstream and V-Upstream arrangements. The tube diameter, D, is around $0.05 \mathrm{~m}$. The modified V-shaped baffle height, $\mathrm{b}$, is varied in term of blockage ratio, $b / D=0.05-0.25$. The effects of the flow attack angle for the modified V-shaped baffle on heat transfer and flow structure are investigated for laminar regime, $\mathrm{Re}=100-1200$. The case studies for the heat exchanger tube equipped with the modified $\mathrm{V}$-shaped baffle are concluded as table 1 .
Table 1 Case study.

\begin{tabular}{|l|l|}
\hline Flow attack angle, $\boldsymbol{\alpha}$ & $20^{\circ}, 30^{\circ}, 45^{\circ}$ \\
\hline Blockage ratio, BR & $0.05,0.10,0.15,0.20,0.25$ \\
\hline Reynolds number, Re & $100-1200$ \\
\hline Arrangement & V-Downstream, V-Upstream \\
\hline
\end{tabular}

\section{BOUNDARY CONDITION AND ASSUMPTION}

The laminar flow with incompressible condition is considered for the present investigation. The steady condition is set for flow and heat transfer. The thermal properties of the test fluid (air with $\operatorname{Pr}=0.707$ ) are assumed to be constant at the average bulk mean temperature. The convective heat transfer is considered, while the natural convection, body force, viscous dissipation and radiation heat transfer are disregarded. 
The computational domain of the heat exchanger tube equipped with the modified V-shaped baffle is set with boundary condition at the inlet and outlet. The tube wall is set with constant temperature at $310 \mathrm{~K}$. All surfaces of the domain are fixed with no-slip wall condition. The modified V-shaped baffle is assumed as insulator. The boundary condition of the computational domain is depicted as Fig. 1.

\section{MATHEMATICAL FOUNDATION AND NUMERICAL METHOD}

The heat exchanger tube equipped with the modified V-shaped baffle is governed by the continuity, the Navier-Stokes equations and the energy equation. The energy equation is discretized by the QUICK scheme, while the governing equations are discretized by power law scheme. The investigation on heat transfer and flow pattern in the heat exchanger tube equipped with the modified V-shaped baffle is resolved by finite volume method with SIMPLE algorithm. The solutions are considered to be converged when the normalized residual values are less than $10^{-5}$ for all variables, but less than $10^{-9}$ only for the energy equation.

The important parameters for the present investigation are reported in term of dimensionless. The velocity of the test fluid at the inlet is reported in terms of the Reynolds number.

The Reynolds number is calculated as:

$\operatorname{Re}=\rho \bar{u} D / \mu$

The pressure loss across the test section inserted with the modified $\mathrm{V}$-shaped baffle is concluded in term of the friction factor ratio. The friction factor, $f$, is calculated from the pressure drop, $\Delta p$, across the periodic module, $L$.

$f=\frac{(\Delta p / L) D}{\frac{1}{2} \rho \bar{u}^{2}}$

The heat transfer rate is displayed in terms of local Nusselt number and average Nusselt number. The local heat transfer is measured by:

$N u_{x}=\frac{h_{x} D}{k}$

The average Nusselt number can be obtained by

$N u=\frac{1}{A} \int N u_{x} \partial A$

The thermal performance of the heating section when equipped with the modified V-shaped baffle is presented in form of thermal enhancement factor. The thermal enhancement factor $(T E F)$ is calculated by the augmentations on both heat transfer and friction factor at similar pumping power.

$T E F=\left.\frac{h}{h_{0}}\right|_{p p}=\left.\frac{N u}{N u_{0}}\right|_{p p}=\left(N u / N u_{0}\right) /\left(f / f_{0}\right)^{1 / 3}$

The $N u_{0}$ and $f_{0}$ are the Nusselt number and friction factor for the smooth circular tube, respectively.

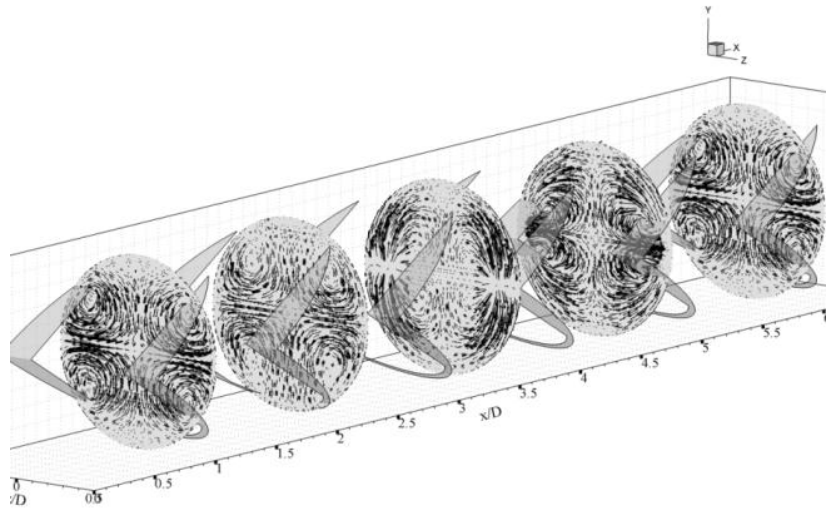

(a)

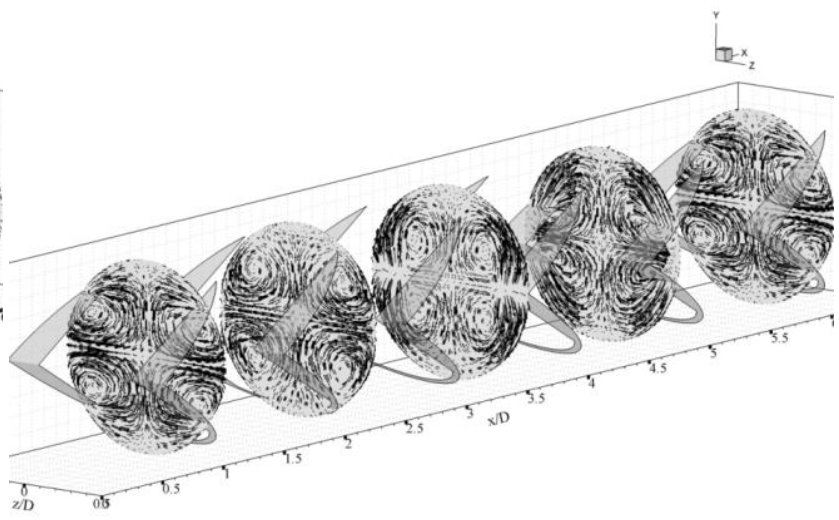

(b)

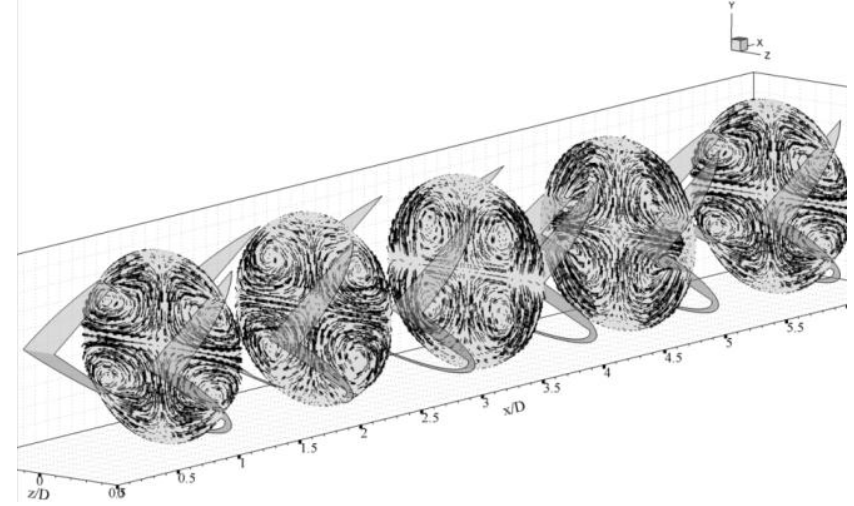

(c)

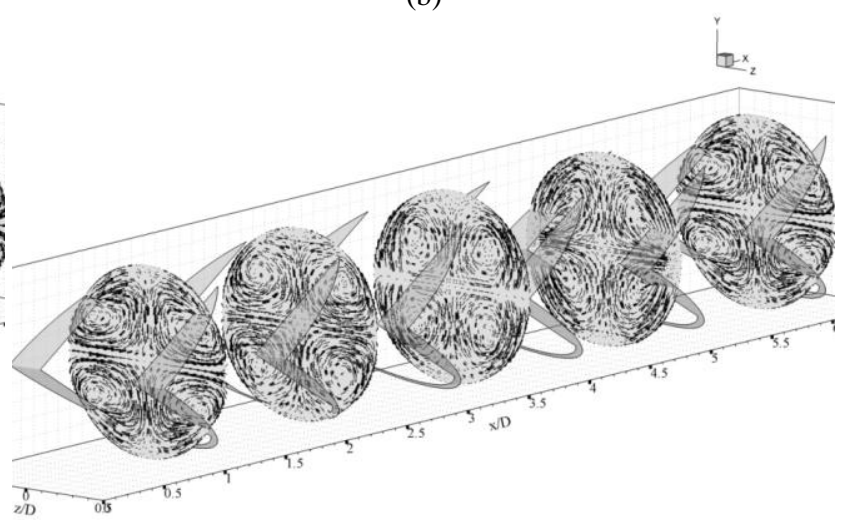

(d)

Fig. 4 Tangential velocity vector in transverse planes for the heat exchanger tube equipped with modified V-shaped baffle of (a) $\operatorname{Re}=100$, (b) $\operatorname{Re}=$ 400 , (c) $\operatorname{Re}=800$ and (d) $\operatorname{Re}=1200$ at $\alpha=30^{\circ}, \mathrm{BR}=0.2$ and V-Upstream.

\section{NUMERICAL VALIDATION}

The computational domain of the heat exchanger tube equipped with the modified V-shaped baffle is validated to ensure that the computational domain has reliability to predict flow and heat transfer mechanisms in the heat exchanger tube. The verifications can divide into two group; verification of the smooth tube and grid independence. Fig. 2 presents the verifications of the smooth tube with no baffle on 
heat transfer rate and pressure loss in terms of the Nusselt number and friction factor, respectively. As the figure, it is found that the friction factor of the present investigation gives slightly higher than the value from the friction factor correlation within $0.3 \%$, while the Nusselt number of the present study performs lower than the value from the Nusselt number correlation within $1 \%$. In conclusion, the deviations on both heat transfer rate and friction loss for the smooth tube are not higher than $5 \%$, therefore, the computational domain has more reliance to investigate the current problem.

The main propose for the grid test is to find the optimum grid cell, which gives high accuracy results and also saves time to investigate and computer resource. Fig. 3 illustrates the comparison on the Nusselt number and friction factor of different grid number for the computational domain of the heat exchanger tube equipped with the modified V-shaped baffle at $\alpha=30^{\circ}, \mathrm{BR}=0.15, \mathrm{~V}$-Upstream arrangement. The five values of grid cells; 80000, 120000, 180000, 220000 and 360000 are compared. As the figure, it is detected that the three sets of grid cells; 180000, 220000 and 360000, provide nearly values on the Nusselt number and friction factor for all Reynolds numbers. Therefore, the grid cells around 180000 are applied for all cases of the present investigation.

\section{NUMERICAL RESULT}

\subsection{Flow and heat transfer mechanisms}

\subsubsection{Effect of Reynolds number}

The heat exchanger tube equipped with the modified V-shaped baffle is compared at different Reynolds numbers. The mechanisms in the test section with various Reynolds number are reported in terms of tangential velocity vector in transverse planes, local temperature contour in transverse plane and local Nusselt number distribution on the heat exchanger tube. Figs. 4a, b, c and d present the tangential velocity vector in cross sectional planes, respectively, for $\mathrm{Re}=100,400,800$ and 1200 in the heat exchanger tube equipped with the modified Vshaped baffle at $\alpha=30^{\circ}, \mathrm{BR}=0.2, \mathrm{~V}$-Upstream. As the figures, the vortex flow, which produced by the modified V-shaped baffle, appears through the test section in all Reynolds numbers. The intensity of the tangential velocity vector increases when increasing the Reynolds number. The $\mathrm{Re}=100$ performs the lowest vortex strength, while the $\operatorname{Re}=1200$ provides the opposite trend.

The flow structure in the test section includes four main vortex flows. The symmetry of the flow structure is detected on left-right part due to the baffle symmetry. The vortex flow is an important factor to enhance heat transfer rate and thermal performance due to the vortex flow helps to improve the fluid mixing and also disturbs the thermal boundary layer on the heat transfer surface.

The heat transfer behavior in term of temperature distributions in transverse planes in the heating section equipped with the modified $\mathrm{V}$ shaped baffle at $\operatorname{Re}=100,400,800$ and 1200 is depicted as Figs. 5a, b, $\mathrm{c}$ and $\mathrm{d}$, respectively, for $\alpha=30^{\circ}, \mathrm{BR}=0.2$ and V-Upstream arrangement. The temperature distribution is an indicator to check the thermal boundary layer near the tube wall and to observe the fluid mixing. As seen in the figures, the insertion of the modified V-shaped baffle in the heat exchanger tube provides a better fluid mixing in all cases. The hot fluid near the tube wall performs thinner, while the cold fluid distributes from the center of the test section. The reason of this may be that the vortex flow, which produced by the modified V-shaped baffle disturbs the thermal boundary layer on the heat transfer surface. It is seen that the temperature distribution in transverse plane for $\mathrm{Re}=$ 100 resembles as the temperature distribution of the smooth tube. The test section with $\operatorname{Re}=1200$ provides the best fluid mixing, while the $\mathrm{Re}$ $=100$ gives the reverse result.

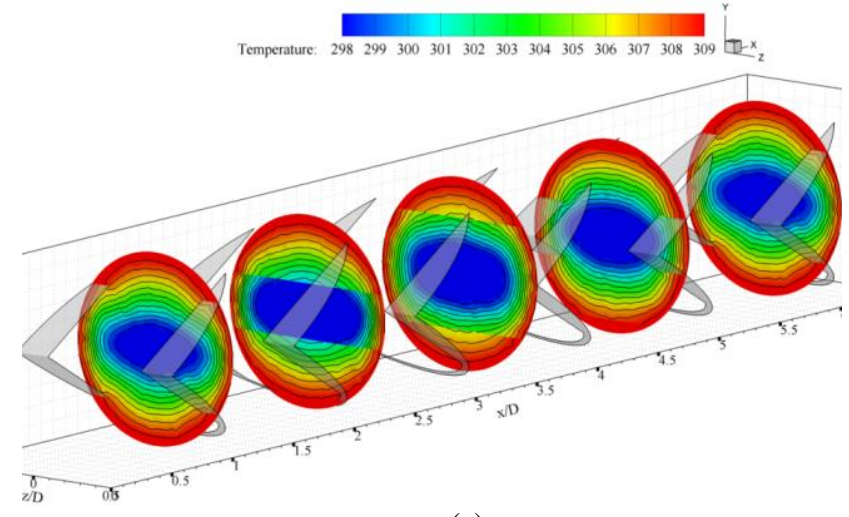

(a)

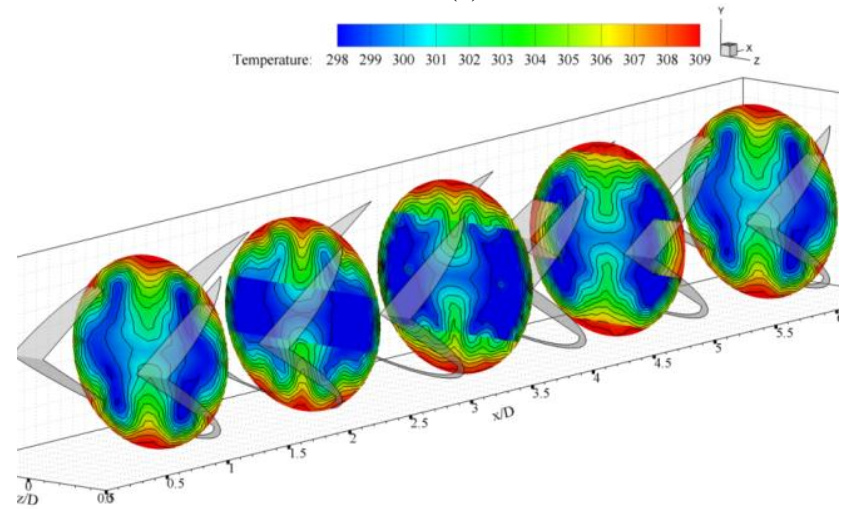

(c)

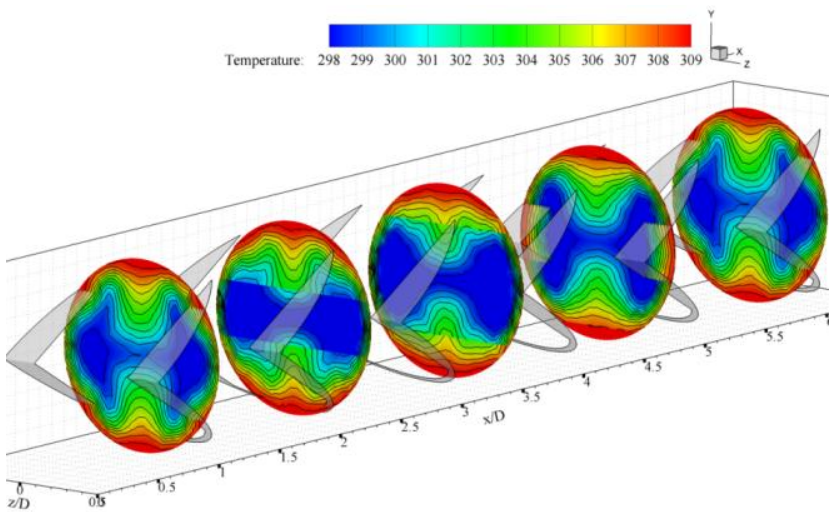

(b)

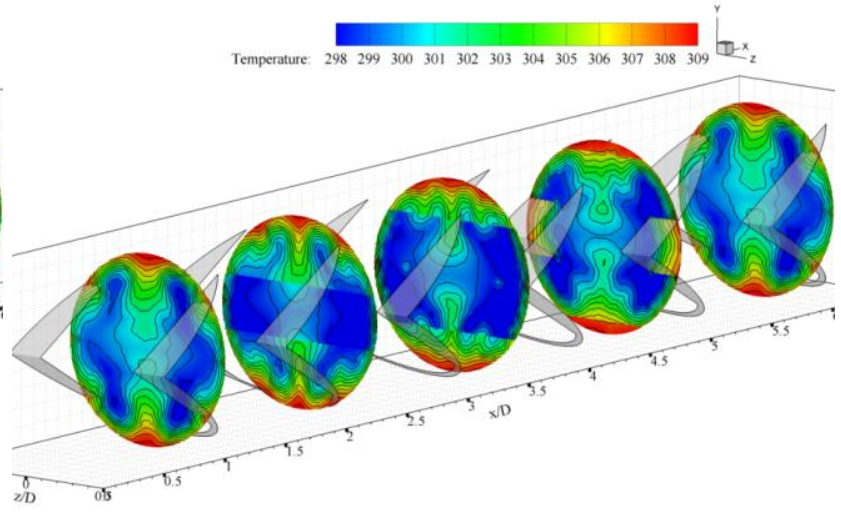

(d)

Fig. 5 Temperature distribution in transverse planes for the heat exchanger tube equipped with modified $\mathrm{V}$-shaped baffle of (a) $\mathrm{Re}=100$, (b) $\mathrm{Re}=$ 400 , (c) $\operatorname{Re}=800$ and (d) $\operatorname{Re}=1200$ at $\alpha=30^{\circ}, \mathrm{BR}=0.2$ and V-Upstream. 
Figs. 6a, b, c and d display the local Nusselt number distributions on the heat exchanger tube equipped with the modified $\mathrm{V}$-shaped baffle at $\mathrm{Re}=100,400,800$ and 1200 , respectively, for $\alpha=30^{\circ}, \mathrm{BR}=0.2$, VUpstream arrangement. The high heat transfer rate shows with red contour, while the low heat transfer rate displays with blue contour. The heat transfer rate increases when augmenting the Reynolds number. The heating section with $\operatorname{Re}=1200$ gives the highest heat transfer rate, while the $\operatorname{Re}=100$ provides the lowest value. The cause is the $\operatorname{Re}=$ 1200 can produce the highest vortex strength.

\subsubsection{Effect of blockage ratio}

The influences of the baffle height $(\mathrm{b} / \mathrm{D}=0.05,0.10,0.15,0.20$ and 0.25 ) on heat transfer rate, pressure loss and thermal performance are considered. The flow structure is depicted in form of the tangential velocity vector in transverse plane, while the heat transfer behavior in the heating section is presented in forms of temperature distribution in transverse plane and local Nusselt number distribution on the heat transfer surface. Figs. $7 \mathrm{a}, \mathrm{b}, \mathrm{c}, \mathrm{d}$ and e report the tangential velocity vector in transverse planes for the heat exchanger tube equipped with the modified V-shaped baffle at $\mathrm{BR}=0.05,0.10,0.15,0.20$ and 0.25 , respectively, of $\alpha=45^{\circ}, \operatorname{Re}=400$, V-Upstream arrangement. As the figures, the vortex flow is detected for the heating section with $\mathrm{BR}=$
$0.15-0.25$. The enhancement of the vortex strength is found when augmenting the baffle height. The $\mathrm{BR}=0.25$ performs the highest vortex intensity, while the $\mathrm{BR}=0.05$ gives the opposite result.

Figs. 8a, b, c, d and e report the temperature distribution in transverse planes for the heat exchanger tube equipped with the modified V-shaped baffle at $\mathrm{BR}=0.05,0.10,0.15,0.20$ and 0.25 , respectively, for $\mathrm{Re}=400, \alpha=30^{\circ}$, V-Upstream arrangement. The heat exchanger tube inserted with $\mathrm{BR}=0.25$ performs the highest vortex strength, therefore, the best fluid mixing is detected in this case. The heating tube placed with the modified V-shaped baffle at $\mathrm{BR}=0.05$ provides the temperature distribution similarly as the smooth tube due to the lowest vortex strength. The thermal boundary layer disturbance is clearly detected at $\mathrm{BR}=0.20$ and 0.25 .

Figs. 9a, b, c, d and e illustrate the local Nusselt number distribution on the heat transfer surface of the heat exchanger tube equipped with the modified $\mathrm{V}$-shaped baffle for $\mathrm{BR}=0.05,0.10,0.15$, 0.20 and 0.25 , respectively, at $\mathrm{Re}=400, \alpha=30^{\circ}$, V-Upstream arrangement. The highest heat transfer rate is found at $\mathrm{BR}=0.25$ due to the highest vortex strength. The peak of heat transfer surface is found at the upper-lower parts of the tube and near the V-tip. The heat transfer behavior is detected similarly for all cases of the V-Upstream arrangement.

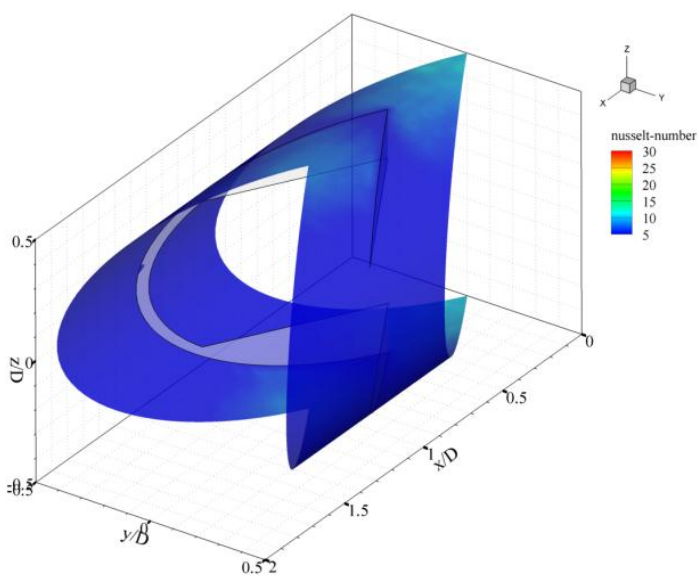

(a)

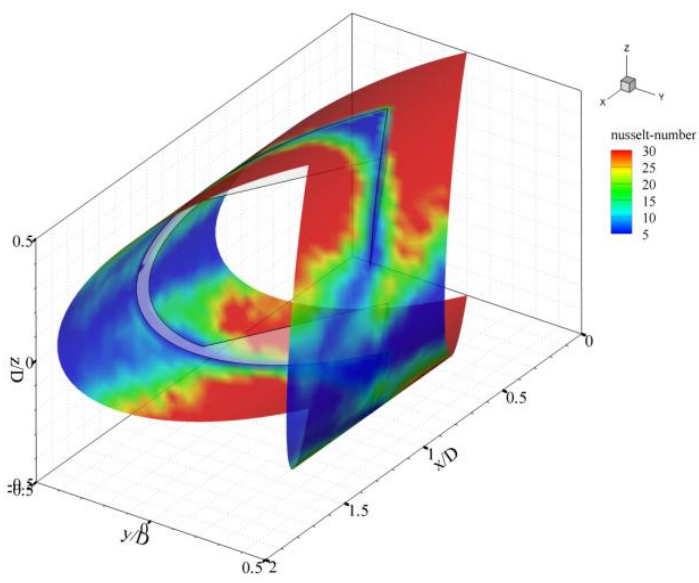

(c)

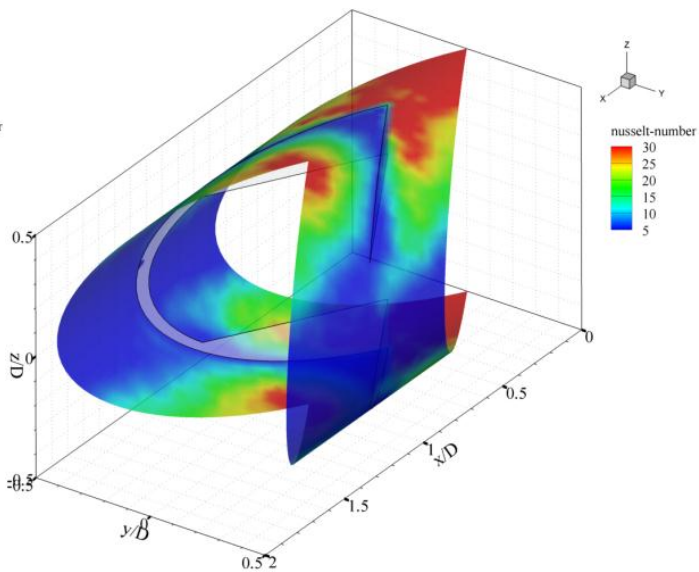

(b)

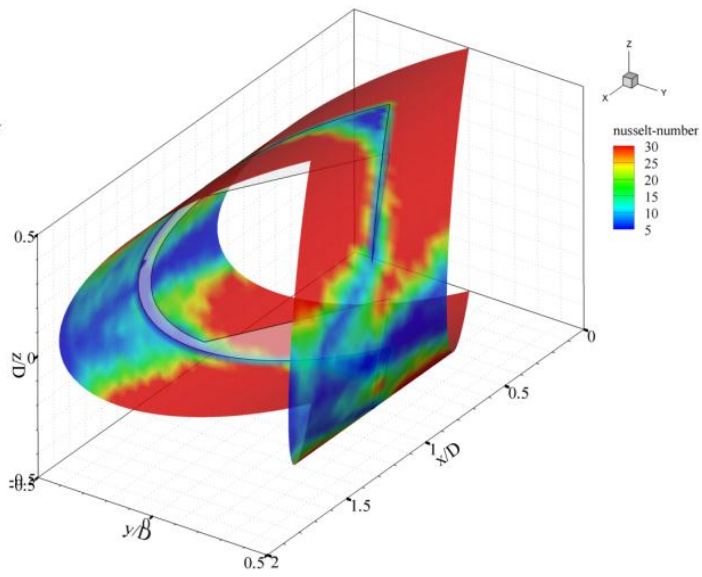

(d)

Fig. 6 Local Nusselt number on the tube wall for the heat exchanger tube equipped with modified V-shaped baffle of (a) $\operatorname{Re}=100$, (b) $\operatorname{Re}=400$, (c) $\operatorname{Re}=800$ and (d) $\mathrm{Re}=1200$ at $\alpha=30^{\circ}, \mathrm{BR}=0.2$ and V-Upstream.

\subsubsection{Effect of flow attack angle}

The effects of the flow attack angle in the heating tube equipped with the modified V-shaped baffle on heat transfer, pressure loss and thermal performance are reported in term of flow and heat transfer mechanisms. Figs. 10a, b and c present tangential velocity vector in transverse planes for the heating section placed with the modified V-shaped baffle at $\alpha=$ $20^{\circ}, 30^{\circ}$ and $45^{\circ}$, respectively, of $\mathrm{BR}=0.15, \mathrm{~V}$-Upstream and $\mathrm{Re}=600$. As the figures, the vortex flow is found in all flow attack angles. The flow pattern of the tube heat exchanger fitted with the modified $\mathrm{V}$ shaped baffle is closely detected. The position of the vortex core depends on the location in the test section. 
Figs. 11a, b and c display temperature distribution in transverse planes for the heat exchanger tube equipped with the modified $\mathrm{V}$ shaped baffle of $\alpha=20^{\circ}, 30^{\circ}$ and $45^{\circ}$, respectively, at $\mathrm{Re}=600, \mathrm{BR}=$ 0.15 and V-Upstream arrangement. The heat transfer behavior with various flow attack angles of the modified V-shaped baffle is similarly found. The high temperature near the tube wall performs thinner, especially, at the left and right part of the plane, while the low temperature at the center of the plane distributes to the heat transfer surface.

Figs. 12a, b and $\mathrm{c}$ report the local Nusselt number distribution on the heat transfer surface of the heat exchanger tube equipped with the modified $\mathrm{V}$-shaped baffle for $\alpha=20^{\circ}, 30^{\circ}$ and $45^{\circ}$, respectively, at $\operatorname{Re}=$ $600, \mathrm{BR}=0.15$, V-Upstream arrangement. As the figures, the peak of the Nusselt number is detected at the upper-lower parts of the tube wall for all flow attack angles, while the left-right parts of the test tube provides the lowest value of heat transfer rate. The high heat transfer rate region appears due to the disturbance of the thermal boundary layer, which acted by the vortex flow.

\subsubsection{Effect of generators arrangement}

Figs. 13a and $\mathrm{b}$ present the tangential velocity vector in cross sectional view of the heating tube equipped with the modified $\mathrm{V}$-shaped baffle at $\mathrm{Re}=400, \mathrm{BR}=0.2, \alpha=20^{\circ}$ for V-Downstream and V-Upstream arrangements, respectively. It is found that the modified $\mathrm{V}$-shaped baffle can produce the vortex flow through the test section for both arrangements. The configuration of the flow pattern includes four main vortex flows. The symmetry flow structure is detected at the upper and lower parts due to the modified V-shaped baffle symmetry. The rotation of the vortex flow reverses when changing the modified $\mathrm{V}$-shaped baffle arrangement. The reversion of the vortex flow effects for the change of the heat transfer behavior in the test section.

Figs. 14a and $\mathrm{b}$ illustrate the temperature distribution in cross sectional view of the test tube fitted with the modified $\mathrm{V}$-shaped baffle respectively, for V-Downstream and V-Upstream arrangements at $\alpha=$ $20^{\circ}, \mathrm{BR}=0.2$ and $\mathrm{Re}=400$. The dissimilarity of the temperature pattern is found when changing the modified $\mathrm{V}$-shaped baffle arrangement. The thermal boundary layer disturbance is clearly detected at the left-right part for V-Downstream arrangement, while obviously found at the upper-lower part for V-Upstream arrangement. The difference of the heat transfer behavior is due to the different flow pattern at various the modified $\mathrm{V}$-shaped baffle arrangements.

Figs. 15a and $\mathrm{b}$ present the local Nusselt number distribution on the tube wall when inserts the modified V-shaped baffle with VDownstream and V-Upstream arrangements in the test section, respectively, for $\alpha=20^{\circ}, \mathrm{BR}=0.20, \operatorname{Re}=400$. The peak of heat transfer rate is detected at the left-right part and upper-lower part for the modified V-shaped baffle with V-Downstream and V-Upstream, respectively. In addition, the V-Downstream creates the vortex flow, which disturbs the thermal boundary layer at the left-right part of the heating section, while the thermal boundary layer disturbance, which acts by the vortex flow for V-Upstream, is found at the upper-lower part.

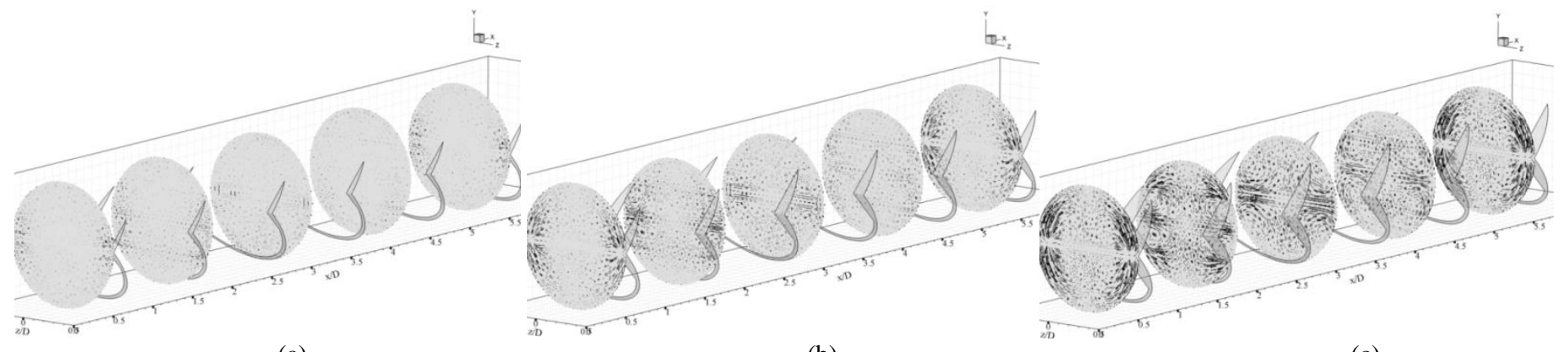

(a)

(b)

(c)

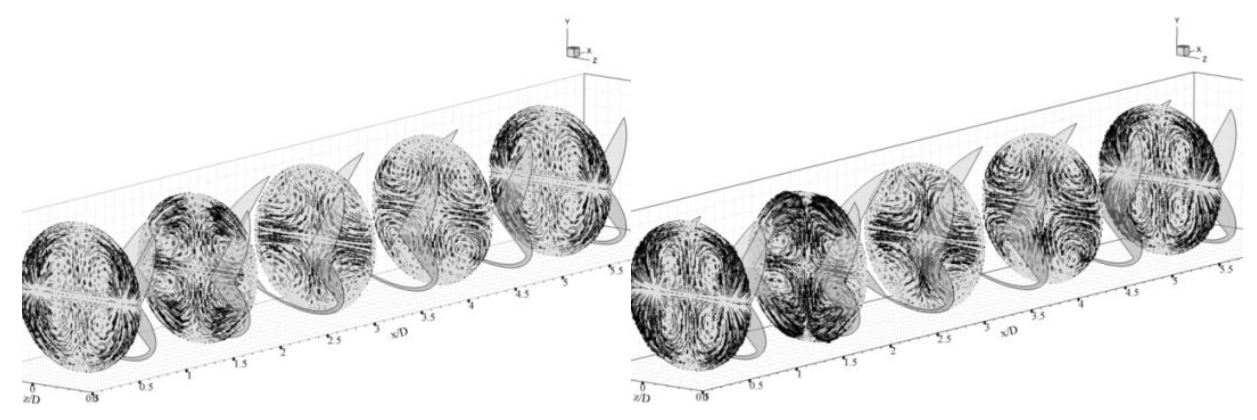

(d)

(e)

Fig. 7 Tangential velocity vector in transverse planes for the heat exchanger tube equipped with modified V-shaped baffle of (a) BR $=0.05$, (b) BR $=0.10$, (c) $\mathrm{BR}=0.15$, (d) $\mathrm{BR}=0.20$ and (e) $\mathrm{BR}=0.25$ at $\alpha=45^{\circ}, \mathrm{Re}=400$ and V-Downstream. 


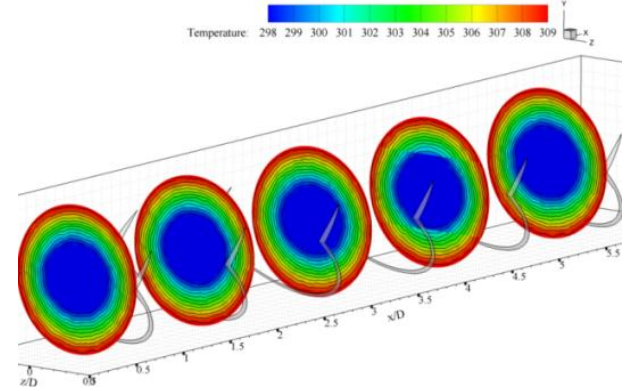

(a)

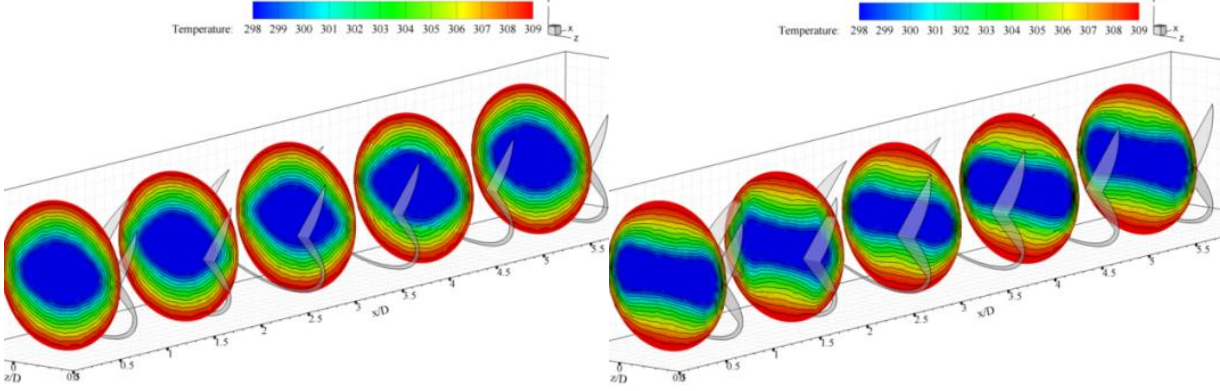

(b)

(c)

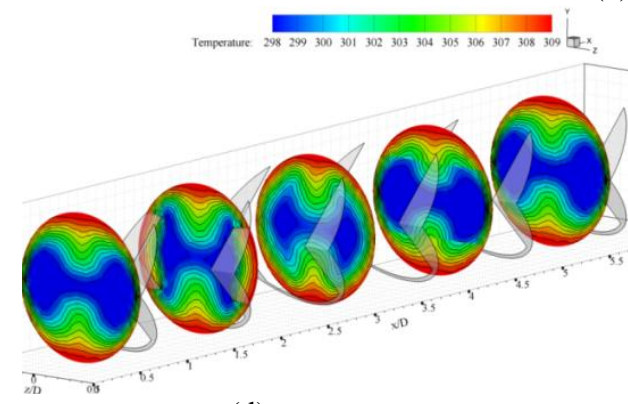

(d)

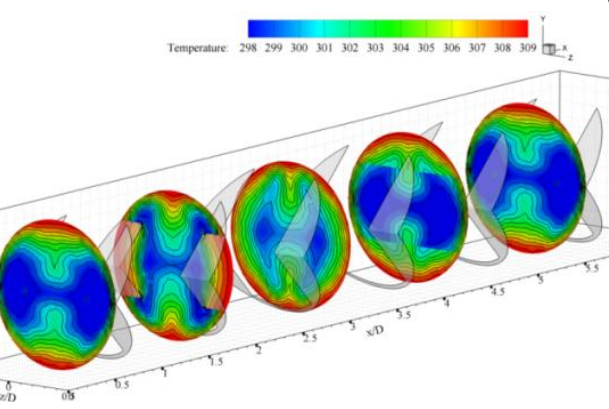

(e)

Fig. 8 Temperature distribution in transverse planes for the heat exchanger tube equipped with modified V-shaped baffle of (a) BR $=0.05$, (b) BR $=0.10$, (c) $\mathrm{BR}=0.15$, (d) $\mathrm{BR}=0.20$ and (e) $\mathrm{BR}=0.25$ at $\alpha=45^{\circ}, \mathrm{Re}=400$ and V-Downstream.

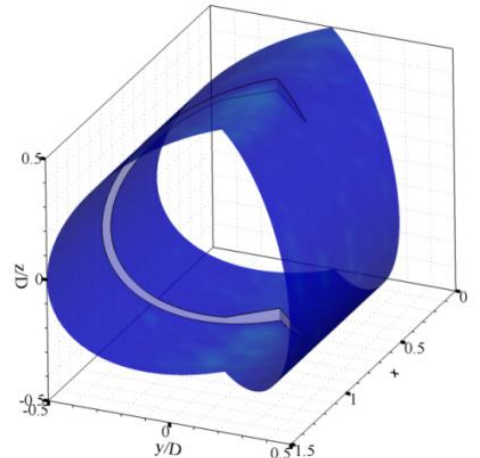

(a)
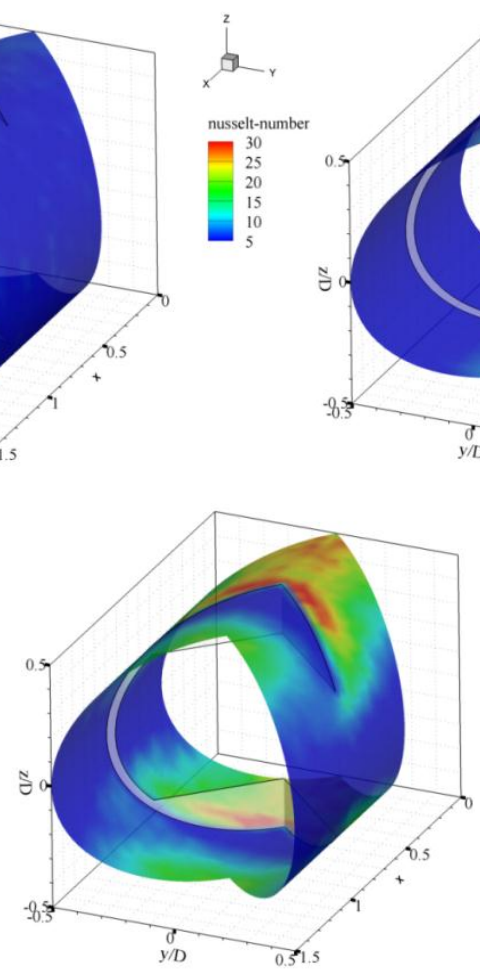

(d)

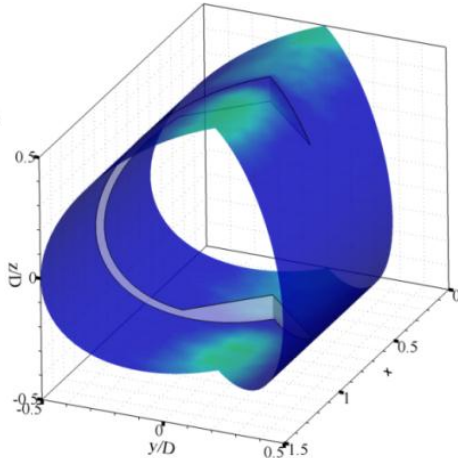

(b)
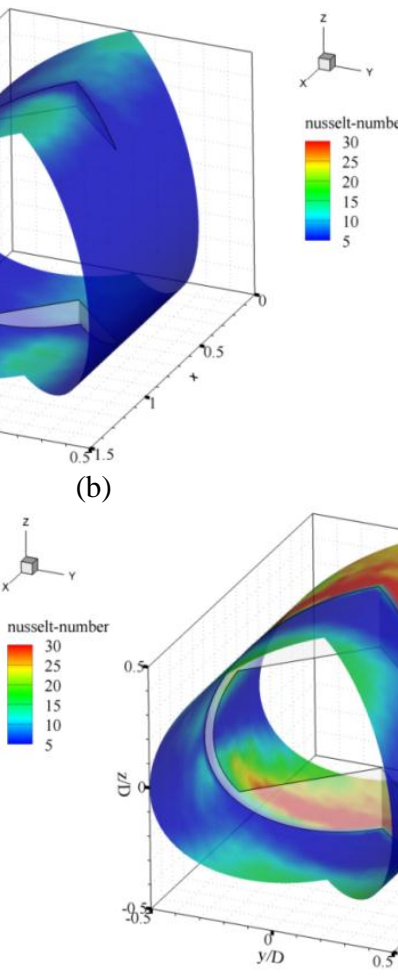

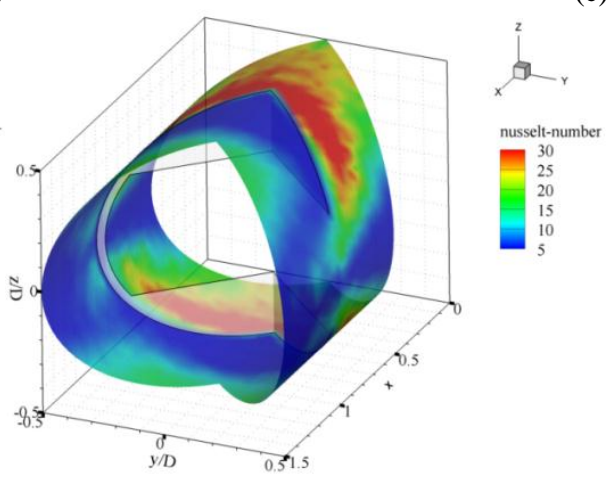

(e)

(c)

Fig. 9 Local Nusselt number on the tube wall for the heat exchanger tube equipped with modified $\mathrm{V}$-shaped baffle of (a) $\mathrm{BR}=0.05$, (b) $\mathrm{BR}=0.10$, (c) $\mathrm{BR}=0.15$, (d) $\mathrm{BR}=0.20$ and (e) $\mathrm{BR}=0.25$ at $\alpha=45^{\circ}, \mathrm{Re}=400$ and V-Downstream. 


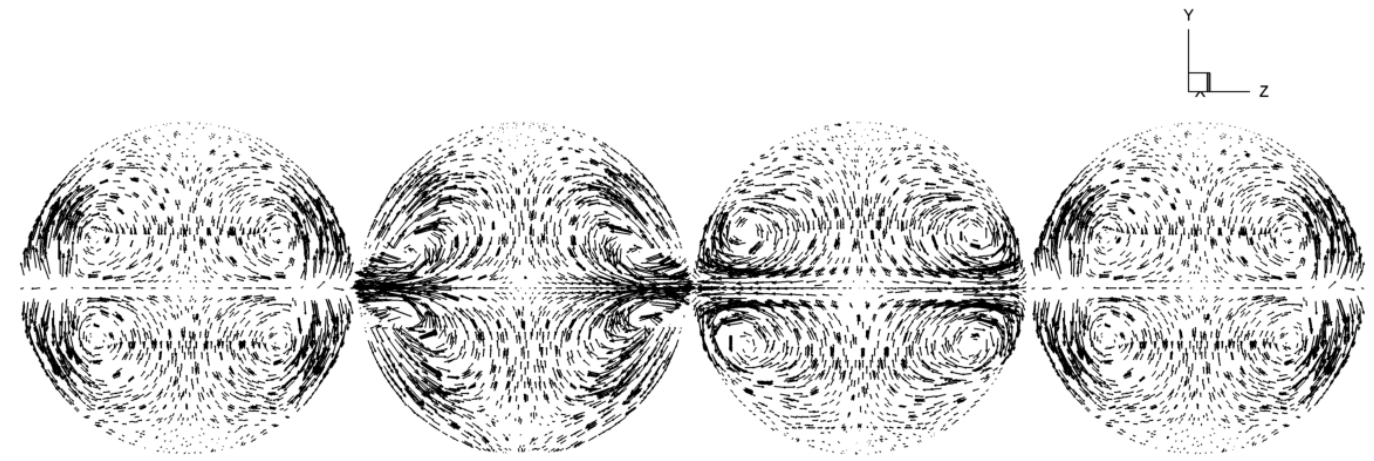

(a)

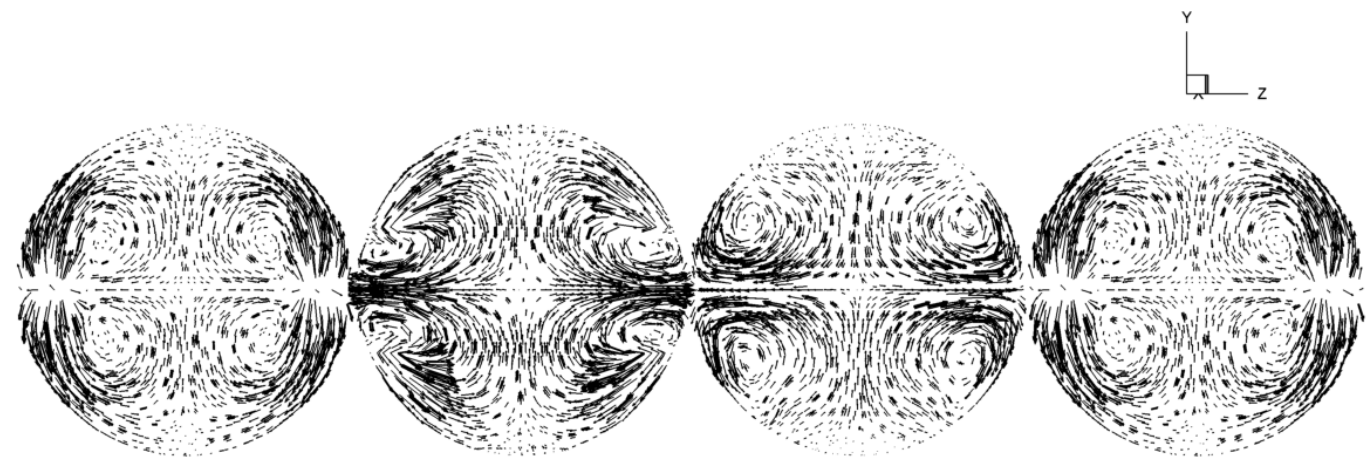

(b)
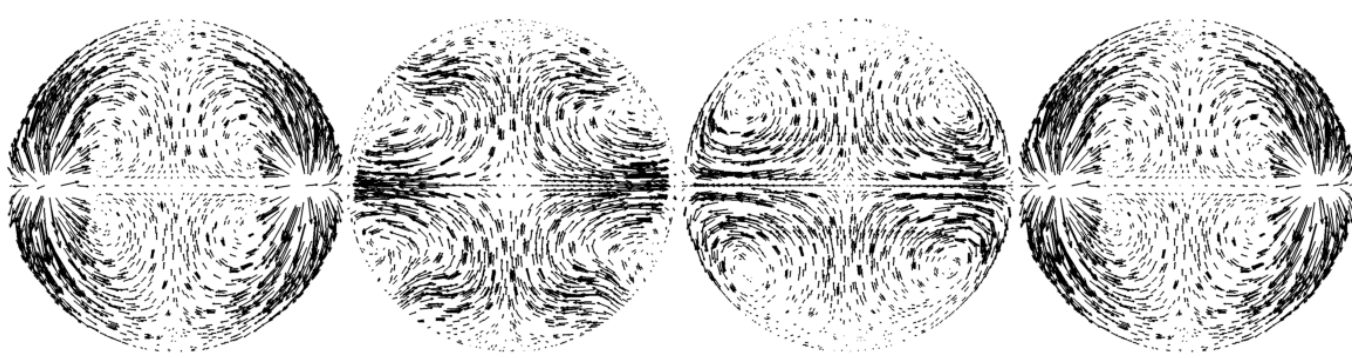

(c)

Fig. 10 Tangential velocity vector in transverse planes for the heat exchanger tube equipped with modified V-shaped baffle of (a) $\alpha=20^{\circ}$, (b) $\alpha=$ $30^{\circ}$ and (c) $\alpha=45^{\circ}$ at $\mathrm{BR}=0.15, \mathrm{Re}=600$ and V-Upstream.

\subsection{Performance assessment}

\subsubsection{Effect of Reynolds number}

The thermal performance analysis in the heat exchanger tube equipped with the modified V-shaped baffle is reported in terms of the Nusselt number ratio $\left(\mathrm{Nu} / \mathrm{Nu}_{0}\right)$, friction factor ratio $\left(\mathrm{f} / \mathrm{f}_{0}\right)$ and thermal enhancement factor (TEF). The numerical results in this part are divided into 4 sections; effect of Reynolds number, effect of BR, effect of flow attack angle and effect of the modified $\mathrm{V}$-shaped baffle arrangement.

Figs. $16 \mathrm{a}, \mathrm{b}$ and $\mathrm{c}$ report the relation of the $\mathrm{Nu} / \mathrm{Nu}_{0}$ with the Reynolds number for the heat exchanger tube equipped with the modified V-shaped baffle at $\alpha=20^{\circ}, 30^{\circ}$ and $45^{\circ}$, respectively.
Generally, the addition of the modified V-shaped baffle in the test section can improve the heat transfer rate greater than the smooth tube with no baffle $\left(\mathrm{Nu} / \mathrm{Nu}_{0}>1\right)$. The $\mathrm{Nu} / \mathrm{Nu}_{0}$ increases when enhancing the Reynolds number for all flow attack angles. The $\mathrm{Re}=1200$ gives the highest heat transfer rate, while the $\mathrm{Re}=100$ performs the lowest value. The reason is the $\operatorname{Re}=1200$ can produce the strongest vortex strength, which extremely disturbs the thermal boundary layer on the heat transfer surface. For $\alpha=20^{\circ}$, the $\mathrm{Nu} / \mathrm{Nu}_{0}$ is around $1.26-1.63$ and 2.09 -7.87 , respectively, for $\mathrm{Re}=100$ and 1200 . The Nusselt number is found to be around $1.02-1.67$ and $2.10-9.43$ times above the smooth tube, respectively, for $\operatorname{Re}=100$ and 1200 at $\alpha=30^{\circ}$. For $\alpha=45^{\circ}$, the $\mathrm{Nu} / \mathrm{Nu}_{0}$ is detected around $1.00-1.60$ for $\mathrm{Re}=100$, while around 2.00 -9.72 for $\mathrm{Re}=1200$. 

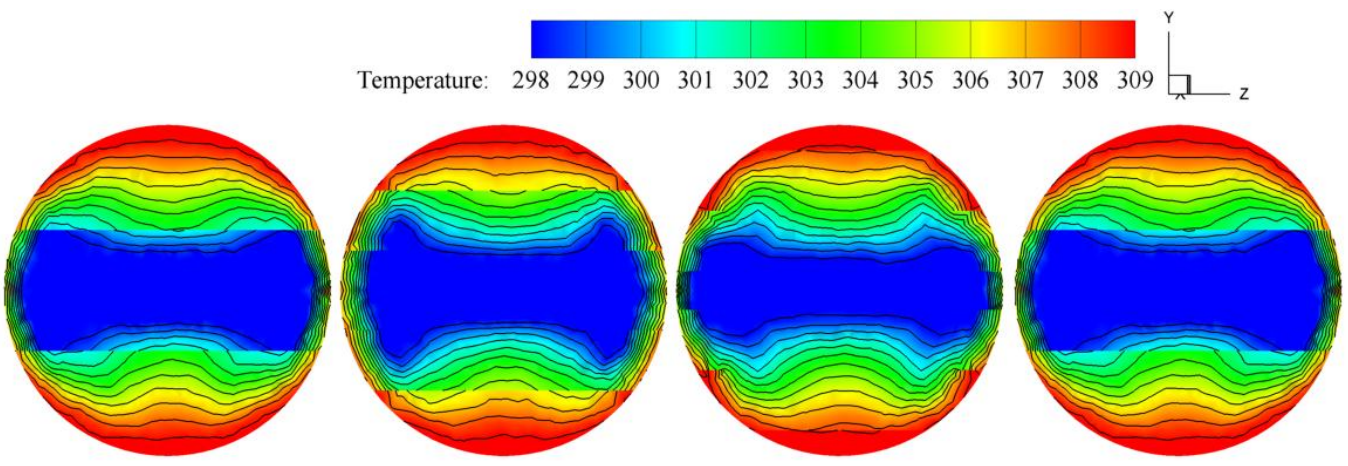

(a)
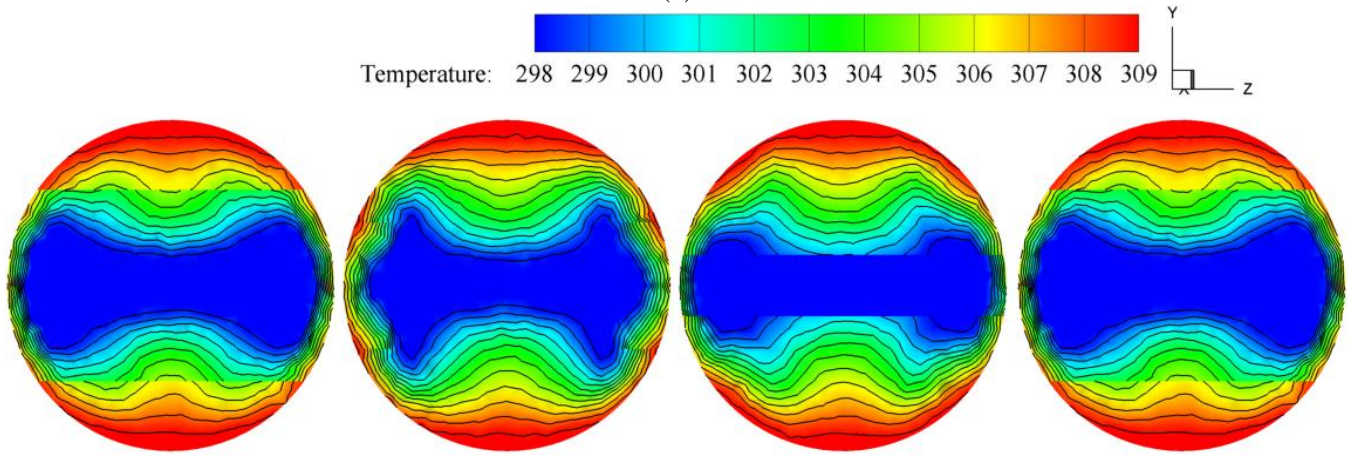

(b)
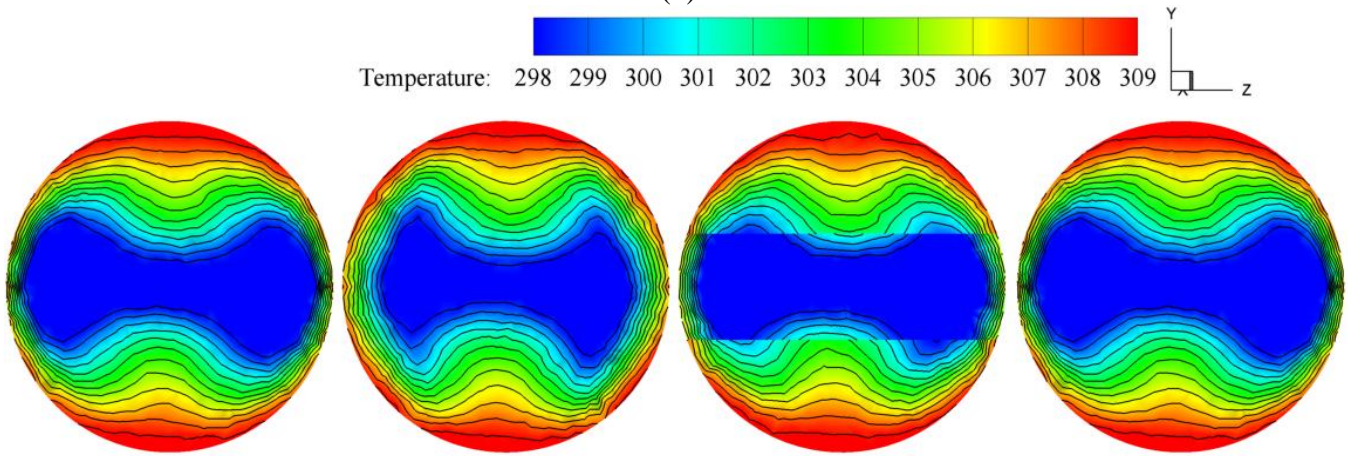

(c)

Fig. 11 Temperature distribution in transverse planes for the heat exchanger tube equipped with modified $\mathrm{V}$-shaped baffle of (a) $\alpha=20^{\circ},(\mathrm{b}) \alpha=30^{\circ}$ and (c) $\alpha=45^{\circ}$ at $\mathrm{BR}=0.15, \mathrm{Re}=600$ and V-Upstream.

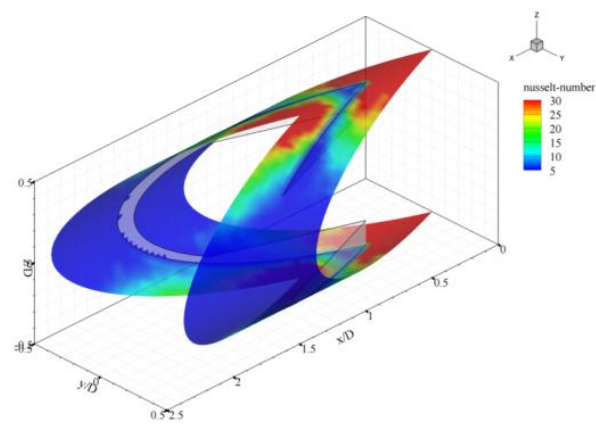

(a)

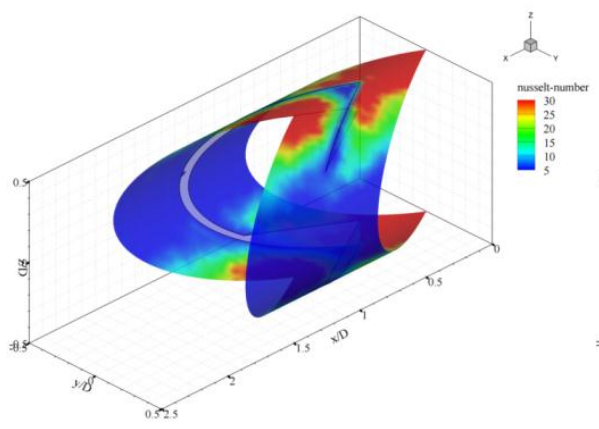

(b)

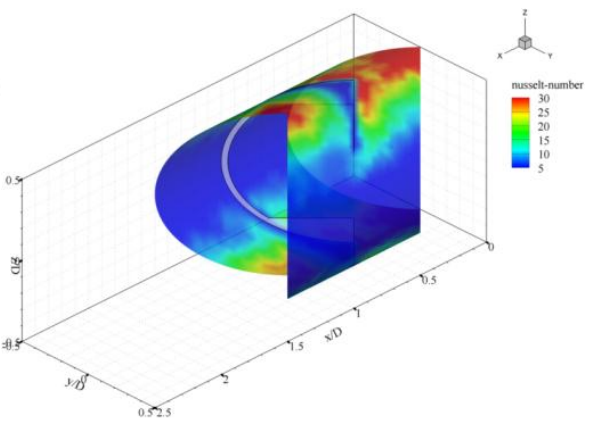

(c)

Fig. 12 Local Nusselt number distribution on the tube wall for the heat exchanger tube equipped with modified V-shaped baffle of (a) $\alpha=20^{\circ}$, (b) $\alpha$ $=30^{\circ}$ and (c) $\alpha=45^{\circ}$ at $\mathrm{BR}=0.15, \mathrm{Re}=600$ and V-Upstream. 


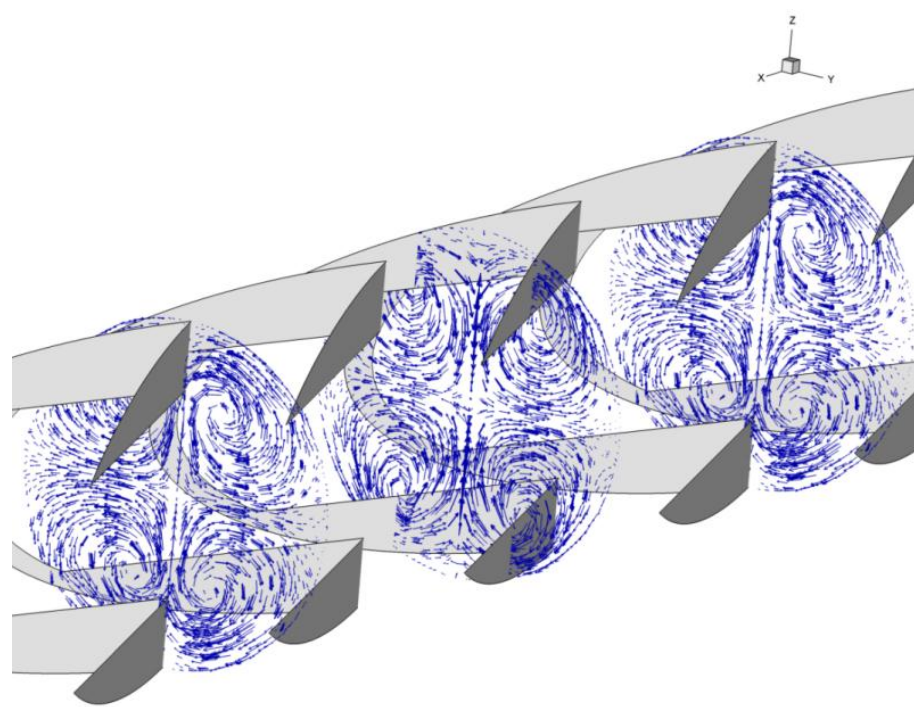

(a)

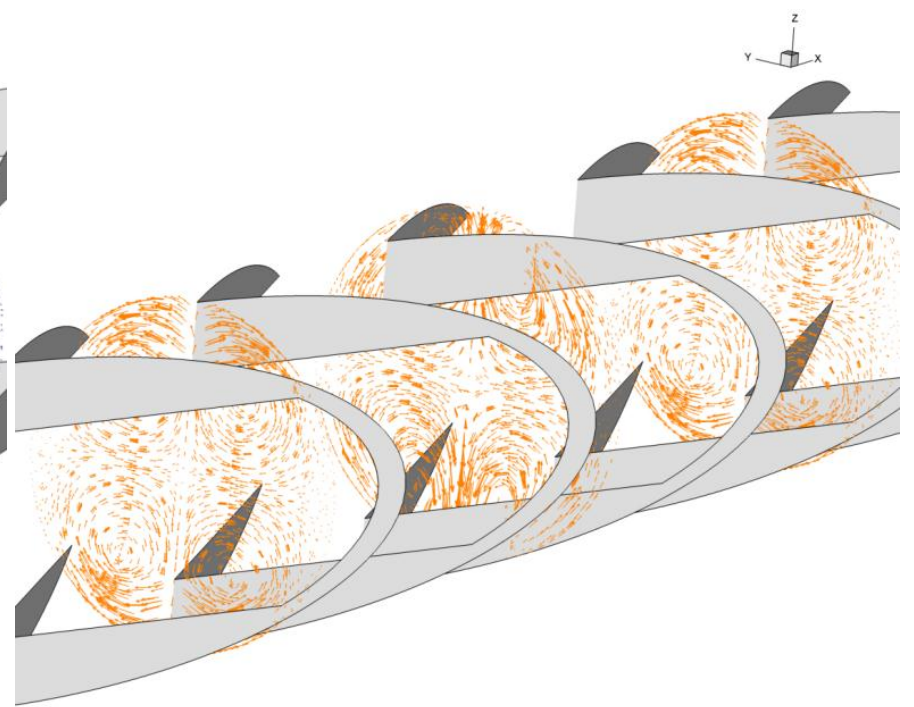

(b)

Fig. 13 Tangential velocity vector in transverse planes for the heat exchanger tube equipped with modified V-shaped baffle of (a) V-Downstream and (b) V-Upstrean at $\alpha=20^{\circ}, \mathrm{BR}=0.2$ and $\mathrm{Re}=400$.

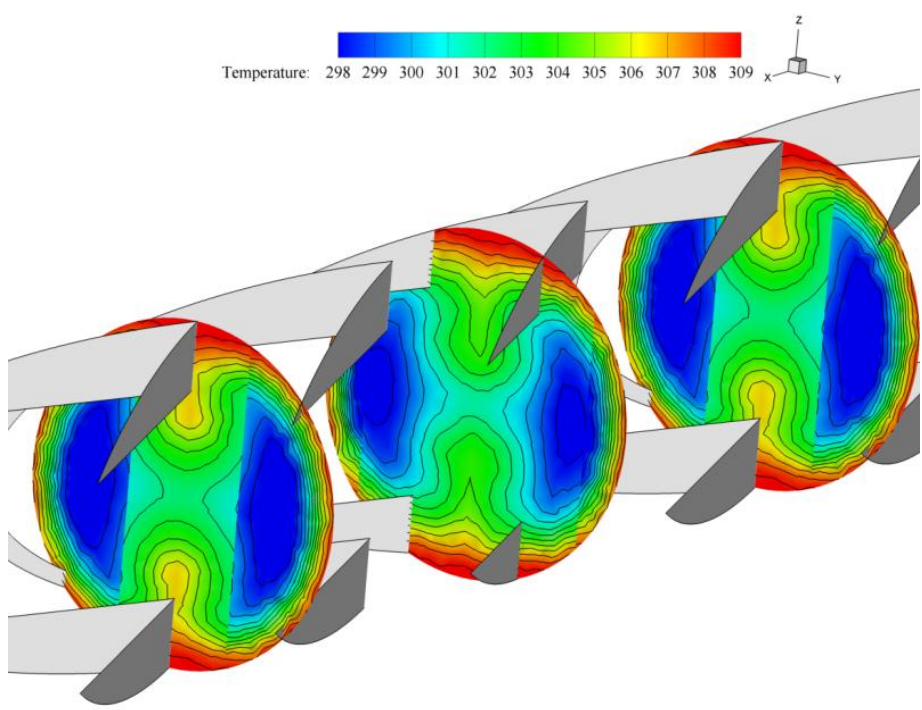

(a)

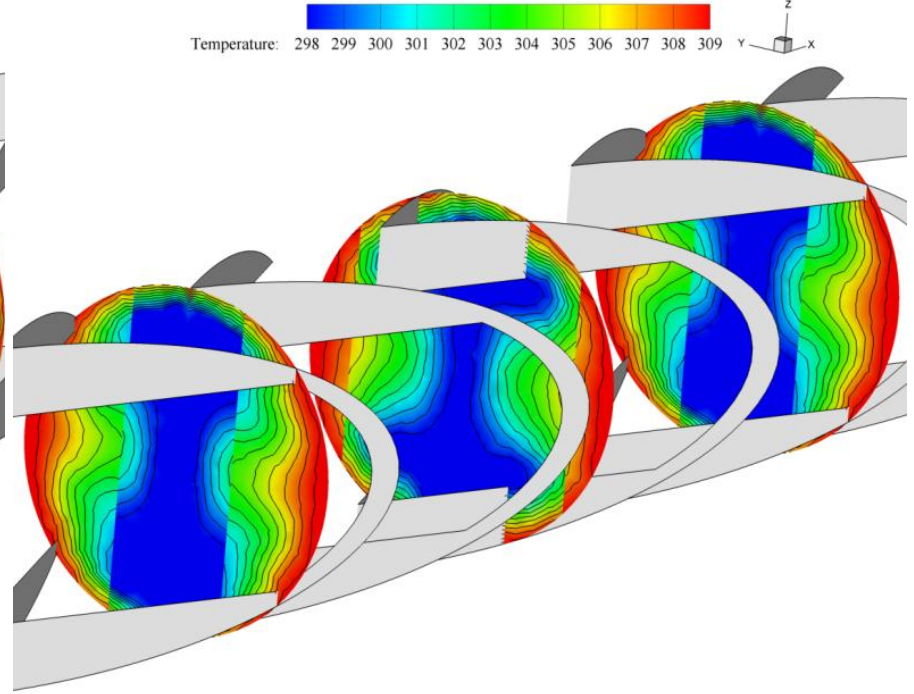

(b)

Fig. 14 Temperature distribution in transverse planes for the heat exchanger tube equipped with modified V-shaped baffle of (a) V-Downstream and (b) V-Upstrean at $\alpha=20^{\circ}, \mathrm{BR}=0.2$ and $\mathrm{Re}=400$.

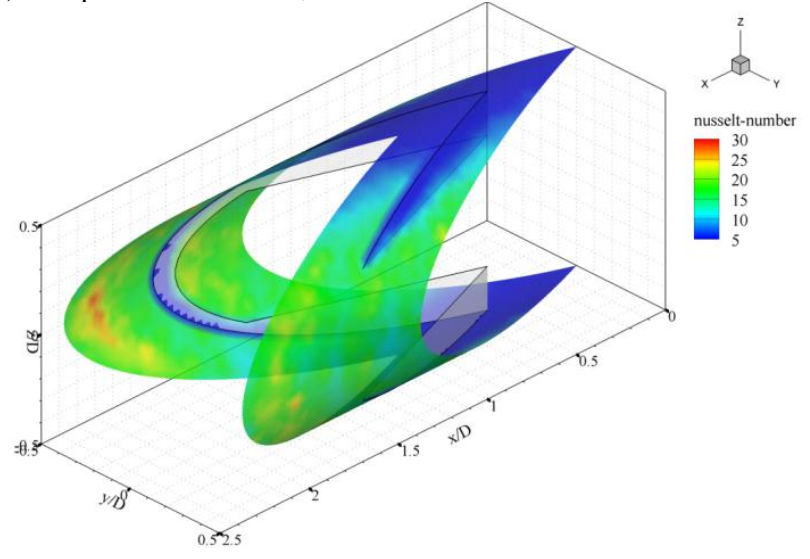

(a)

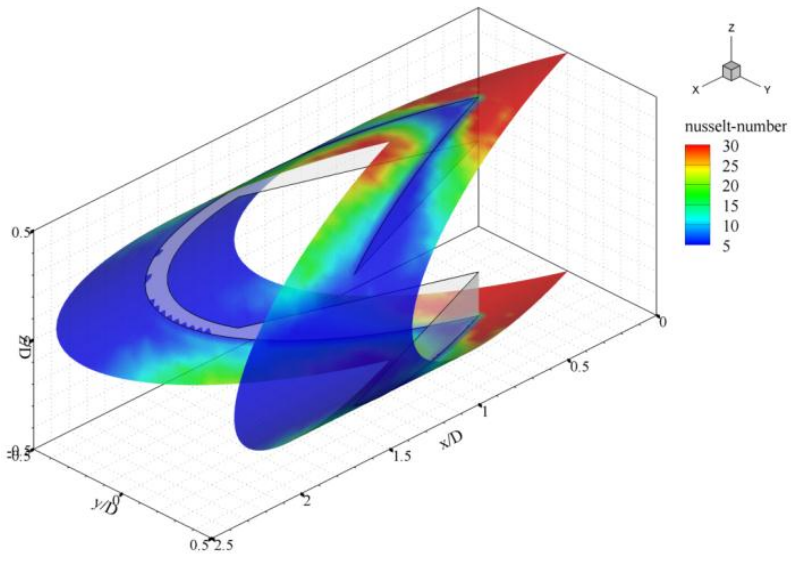

(b)

Fig. 15 Local Nusselt Number distribution on the tube wall for the heat exchanger tube equipped with modified V-shaped baffle of (a) VDownstream and (b) V-Upstrean at $\alpha=20^{\circ}, \mathrm{BR}=0.2$ and $\mathrm{Re}=400$. 
The present of the modified V-shaped baffle in the test section not only increases in heat transfer rate, but also enhances pressure loss. Figs. $17 \mathrm{a}, \mathrm{b}$ and $\mathrm{c}$ depict the relation of the $\mathrm{f} / \mathrm{f}_{0}$ with the Reynolds number for the heating tube placed with the modified $\mathrm{V}$-shaped baffle at the flow attack angle of $20^{\circ}, 30^{\circ}$ and, $45^{\circ}$, respectively. In general, the insertion of the modified $\mathrm{V}$-shaped baffle in the heat exchanger tube provides higher friction loss than the smooth tube $\left(\mathrm{f} / \mathrm{f}_{0}>1\right)$. The $\mathrm{f} / \mathrm{f}_{0}$ augments when enhancing the Reynolds number in all cases. The maximum friction loss is detected at $\operatorname{Re}=1200$, while the minimum value is found at $\operatorname{Re}=100$. The $\mathrm{f} / \mathrm{f}_{0}$ is around $1.44-3.11$ for $\alpha=20^{\circ}$ at $\operatorname{Re}=100$ and 1200, respectively. The modified V-shaped baffle with $\alpha$ $=30^{\circ}$ gives the friction factor around $1.44-3.29$ and $3.91-25.52$ times higher than the smooth tube with no baffle, respectively, for $\mathrm{Re}=100$ and 1200. The $\mathrm{f} / \mathrm{f}_{0}$ for the modified $\mathrm{V}$-shaped baffle with $\alpha=45^{\circ}$ is detected around $1.42-3.26$ at $\operatorname{Re}=100$, while around $3.81-39.34$ for $\operatorname{Re}=1200$.

The relation of the TEF with the Reynolds number for the heating section inserted with the modified V-shaped baffle at $\alpha=20^{\circ}, 30^{\circ}$ and $45^{\circ}$ is reported as Figs. $18 \mathrm{a}, \mathrm{b}$ and c, respectively. Almost cases, the insertions of the modified V-shaped baffle in the tube heat exchanger can develop the TEF upper than the smooth round tube (TEF > 1). The thermal performance enhances when increasing the Reynolds number for all cases. The maximum TEF is detected at $\mathrm{Re}=1200$. The maximum TEF is around 1.13 and 3.07 when considered at $\mathrm{Re}=100$ and 1200, respectively, for $\alpha=20^{\circ}$. The peak of TEF is detected around 1.13 at $\operatorname{Re}=100$, while around 3.22 at $\operatorname{Re}=1200$ for the heat exchanger tube equipped with the $30^{\circ}$ modified $\mathrm{V}$-shaped baffle. For $\alpha$ $=45^{\circ}$, the optimum TEF is around 1.08 and 2.98, respectively, for $\operatorname{Re}=$ 100 and 1200.

\subsubsection{Effect of blockage ratio}

The variation of the $\mathrm{Nu} / \mathrm{Nu}_{0}$ with the blockage ratio for the test tube inserted with the modified V-shaped baffle at $\alpha=20^{\circ}, 30^{\circ}$ and $45^{\circ}$ is depicted as Figs. 19a, b and c, respectively. The increment of the flow blockage ratio leads to increase in heat transfer rate due to the increment of the vortex strength. The maximum and minimum values of the Nusselt number are found at the flow blockage ratio of 0.25 and 0.05 , respectively, for all flow attack angles. The $\mathrm{Nu} / \mathrm{Nu}_{0}$ is found around $0.98-2.21,0.97-4.22,0.96-6.91,1.03-8.22,1.13-9.43$, respectively, for $\mathrm{BR}=0.05,0.10,0.15,0.20$ and 0.25 .

The pressure loss in the heating section places with the modified $\mathrm{V}$-shaped baffle in terms of the friction factor ratio is reported as Figs. $20 \mathrm{a}, \mathrm{b}$ and $\mathrm{c}$ for $\alpha=20^{\circ}, 30^{\circ}$ and $45^{\circ}$, respectively. The augmentation on the flow blockage ratio results in the increase in the pressure loss across the test section, especially, at $\mathrm{BR}=0.25$. The $\mathrm{BR}=0.05$ can help to reduce the pressure loss in the test circular tube. The extreme augmentation of the $\mathrm{f} / \mathrm{f}_{0}$ is detected in the range $0.20 \leq \mathrm{BR} \leq 0.25$. In the range investigates, the $\mathrm{f} / \mathrm{f}_{0}$ is around $1.43-3.93,1.52-5.12,1.67-$ $9.99,1.84-20.61,2.98-39.34$ for $\mathrm{BR}=0.05,0.10,0.15,0.20$ and 0.25 , respectively.

Figs. 21a, b and c report the variation of the TEF with the flow blockage ratio for the heating tube inserted with the modified $\mathrm{V}$-shaped baffle at $\alpha=20^{\circ}, 30^{\circ}$ and $45^{\circ}$, respectively. It is clearly seen in the figures that the heat exchanger tube equipped with the modified Vshaped baffle at $\mathrm{BR}=0.05$ gives the lowest thermal performance. The peak of the TEF is detected in the range $0.15 \leq \mathrm{BR} \leq 0.25$ for all flow attack angle and arrangements. The optimum TEF is around 1.40, 2.45, $3.21,3.22$ and 3.20 , respectively, for $\mathrm{BR}=0.05,0.10,0.15,0.20$ and 0.25 .

\subsubsection{Effect of flow attack angle}

The influences of the flow attack angle for the modified V-shaped baffle on heat transfer rate are plotted with the relation of the $\mathrm{Nu} / \mathrm{Nu}_{0}$ with $\mathrm{Re}$ for $\mathrm{BR}=0.05,0.10,0.15,0.20$ and 0.25 as Figs. 22a, b, c, d and e, respectively. At $\mathrm{BR}=0.05$, the maximum heat transfer rate is found at the flow attack angle of $20^{\circ}$ with V-Downstream arrangement for all Reynolds number. For $\mathrm{BR}=0.10-0.20$ and $\mathrm{Re}=1200$, the optimum Nusselt number is detected at $\alpha=30^{\circ}$, V-Upstream. For BR $=$ 0.25 , the modified $\mathrm{V}$-shaped baffle with the flow attack angle of $45^{\circ}$ and V-Downstream arrangement performs the greatest heat transfer rate when considered at the highest Reynolds number, $\mathrm{Re}=1200$. The Nusselt number of the heat exchanger tube equipped with modified Vshaped baffle is around $1.00-7.87,1.03-9.42$ and $1.00-9.72$ times higher than the smooth round tube for $\alpha=20^{\circ}, 30^{\circ}$ and $45^{\circ}$, respectively.

Figs. 23a, b, c, $d$ and e illustrate the relation of the $f / f_{0}$ with $R e$ at various flow attack angle, Re, and arrangement. For $\mathrm{BR}=0.05$, the pressure loss in the test section is closely found. The $30^{\circ}$ modified $\mathrm{V}$ shaped baffle with $\mathrm{V}$-Downstream provides the highest friction loss for $\mathrm{BR}=0.10$ and 0.15 , while the $45^{\circ}$ modified V-shaped baffle with VUpstream gives the greatest friction loss for $B R=0.20$ and 0.25 . The addition of the modified V-shaped baffle in the heat exchanger tube increases the friction factor around $1.43-18.64,1.44-25.52$ and 1.42 -39.34 time over the smooth tube, respectively, for $\alpha=20^{\circ}, 30^{\circ}$ and $45^{\circ}$.

Figs. 24a, b, c, d and e present the variation of the TEF with Re for the heat exchanger tube inserted with the modified $\mathrm{V}$-shaped baffle at $\mathrm{BR}=0.05,0.10,0.15,0.20$ and 0.25 , respectively. Considering at $\mathrm{Re}=$ 1200 , the optimum TEF is detected at the flow attack angle of $30^{\circ}, \mathrm{V}$ Upstream arrangement, except for $\mathrm{BR}=0.05$. The $\alpha=20^{\circ}$ with $\mathrm{V}$ Downstream gives the highest $\mathrm{TEF}$ for $\mathrm{BR}=0.05$. Additionally, the optimum thermal performance is around 3.07, 3.22 and 2.98 when inserted the modified V-shaped baffle in the tube heat exchanger with $\alpha$ $=20^{\circ}, 30^{\circ}$ and $45^{\circ}$, respectively.

\subsubsection{Effect of generators arrangement}

For $\mathrm{BR}=0.05$, the different arrangement of the modified V-shaped baffle in the heat exchanger tube has no effect for the Nusselt number values of all flow attack angles. The $\mathrm{Nu} / \mathrm{Nu}_{0}$ is found closely for all Reynolds numbers. Considering at $\alpha=20^{\circ}$, Re $>400$, the V-Upstream arrangement provides higher Nusselt number than the V-Downstream arrangement. For $\alpha=30^{\circ}$, the $\mathrm{Nu} / \mathrm{Nu}_{0}$ for the $\mathrm{V}$-Upstream arrangement performs slightly greater than the $\mathrm{V}$-Downstream in the range $\mathrm{Re}=600$ - 1200. At $\alpha=45^{\circ}$, the V-Downstream arrangement gives higher heat transfer rate than the $\mathrm{V}$-Upstream for $\mathrm{BR}=0.20$ and 0.25 . For $\mathrm{BR}=$ $0.15, \operatorname{Re} \geq 600$ and $\alpha=45^{\circ}$, the V-Upstream produces higher heat transfer rate than the V-Downstream. The Nusselt number ratio for the flow attack angle of $45^{\circ}$ is nearly found at the low blockage ratio, BR = 0.05 and 0.10 .

The $\mathrm{f} / \mathrm{f}_{0}$ is closely detected for $\mathrm{BR}=0.05$ and 0.10 of all Reynolds numbers and flow attack angles. For $\alpha=20^{\circ}$ and $30^{\circ}$, the V-Upstream performs higher friction loss than the V-Downstream when $\mathrm{BR}>0.10$. For $\alpha=45^{\circ}$, the V-Downstream gives greater friction factor ratio than the $\mathrm{V}$-Upstream when $\mathrm{BR} \geq 0.20$, but lower for $\mathrm{BR}=0.15$.

The optimum of the thermal enhancement factor is detected at VUpstream case for the flow attack angle of $20^{\circ}$ and $30^{\circ}$, while found at V-Downstream case for the flow attack angle of $45^{\circ}$. 


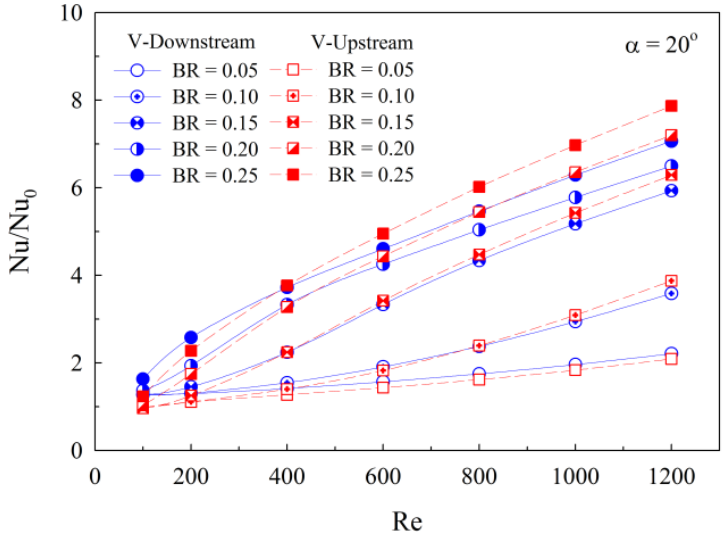

(a)

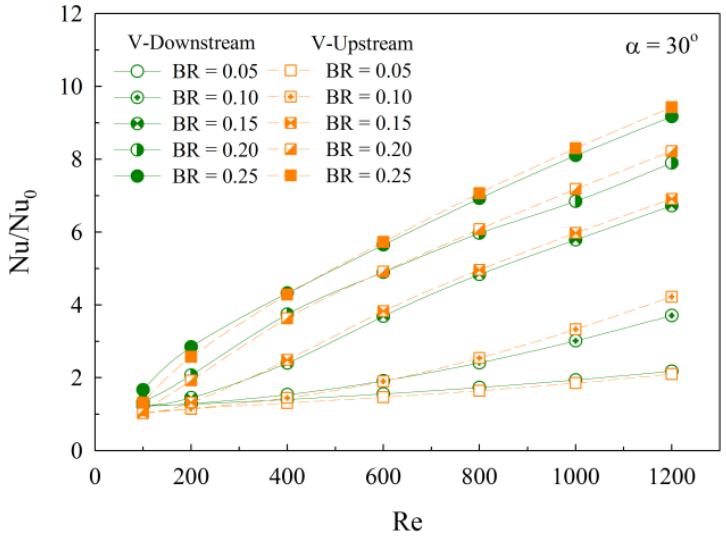

(b)

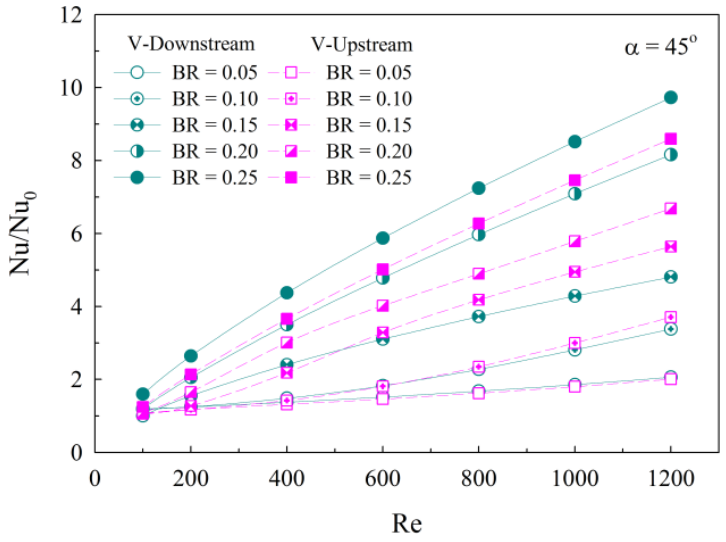

(c)

Fig. $16 \mathrm{Nu} / \mathrm{Nu}_{0}$ versus $\mathrm{Re}$ for (a) $\alpha=20^{\circ}$, (b) $30^{\circ}$ and (c) $45^{\circ}$.

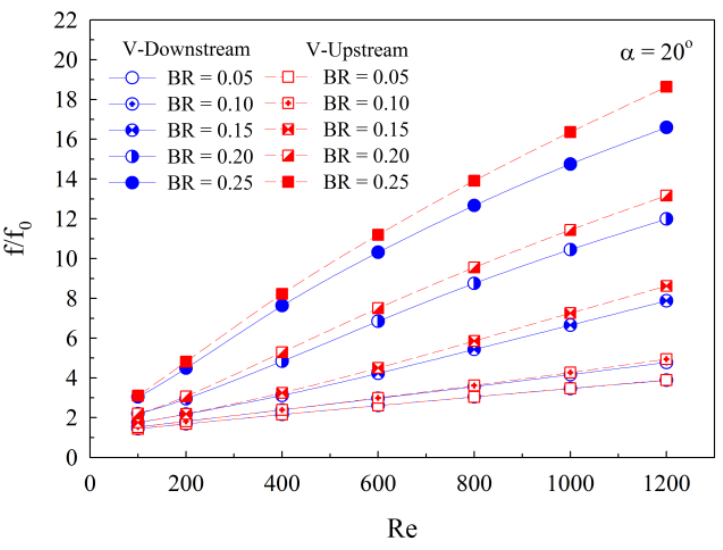

(a)

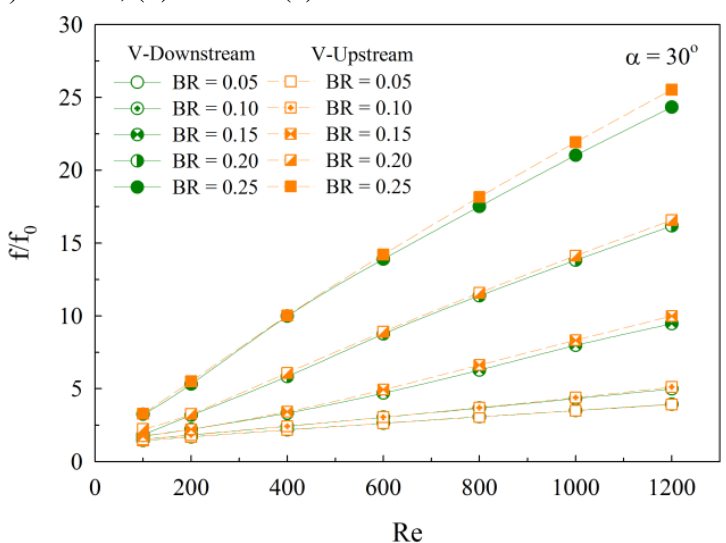

(b)

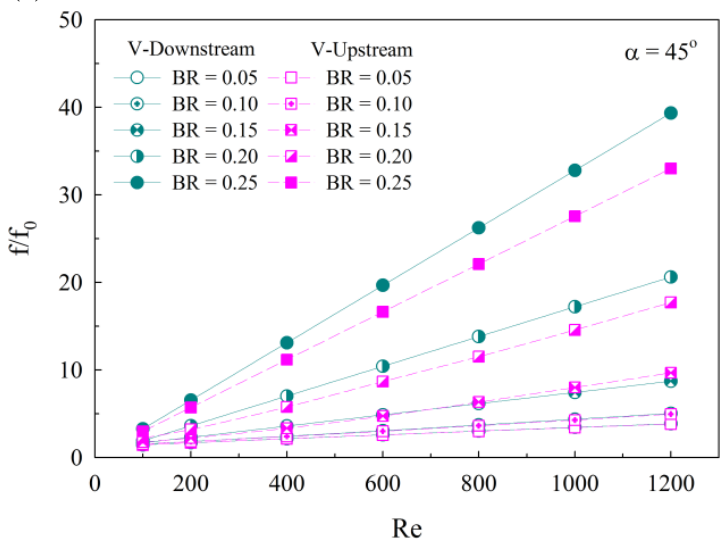

(c)

Fig. $17 \mathrm{f} / \mathrm{f}_{0}$ versus Re for (a) $\alpha=20^{\circ}$, (b) $30^{\circ}$ and (c) $45^{\circ}$. 


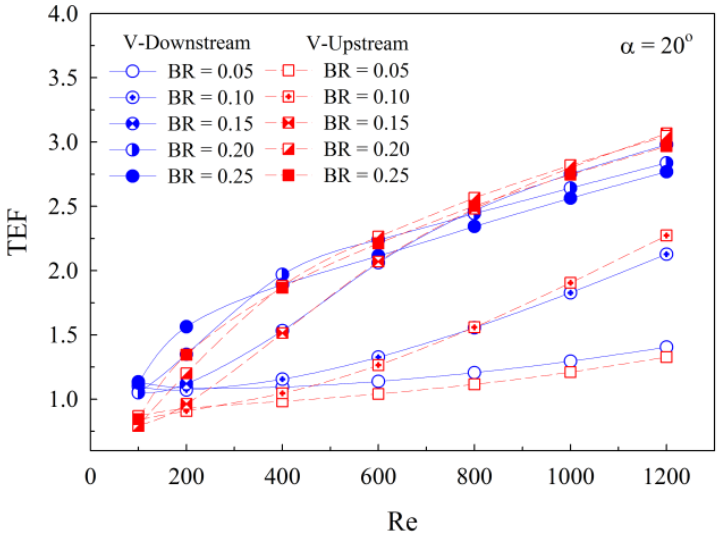

(a)

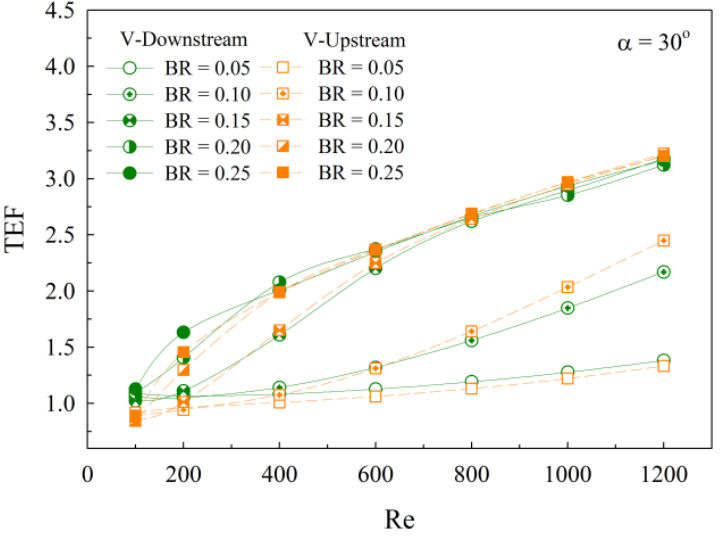

(b)

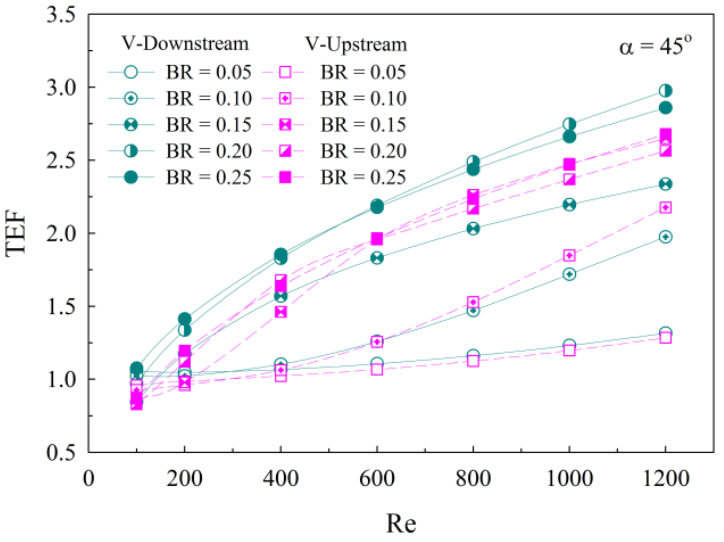

(c)

Fig. $18 \mathrm{TEF}$ versus Re for (a) $\alpha=20^{\circ}$, (b) $30^{\circ}$ and (c) $45^{\circ}$.

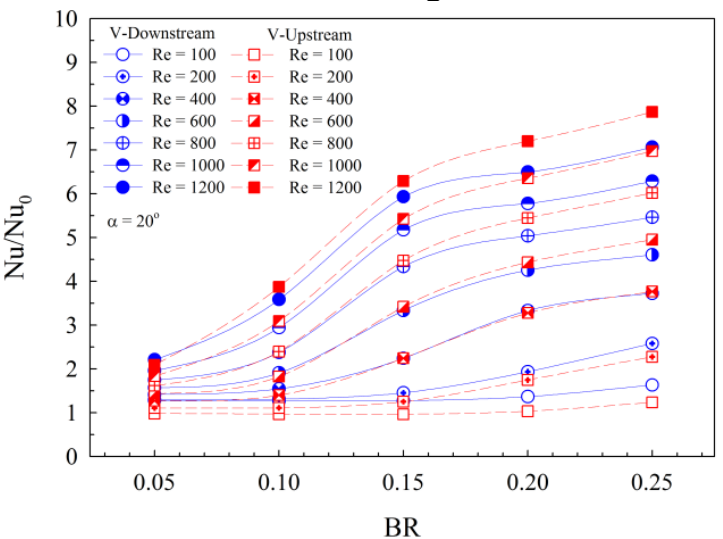

(a)

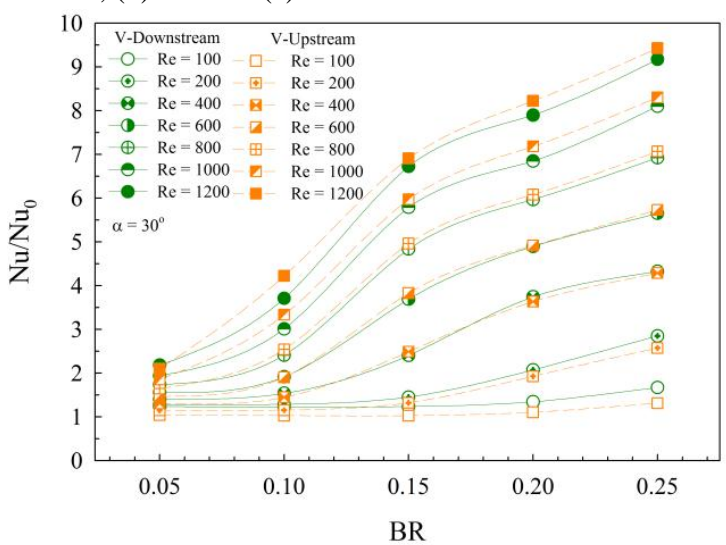

(b)

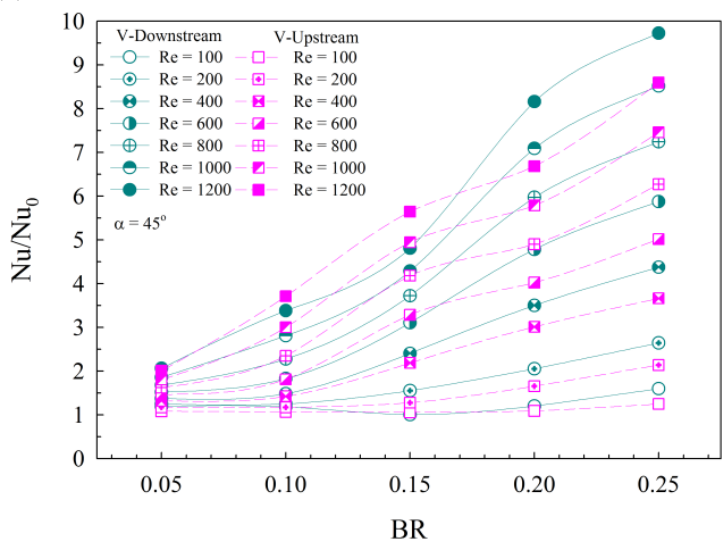

(c)

Fig. $19 \mathrm{Nu} / \mathrm{Nu}_{0}$ versus $\mathrm{BR}$ for (a) $\alpha=20^{\circ}$, (b) $30^{\circ}$ and (c) $45^{\circ}$. 


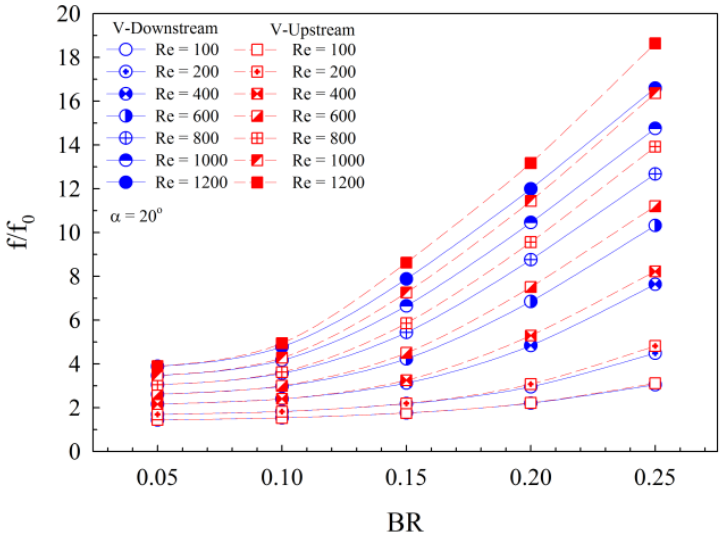

(a)

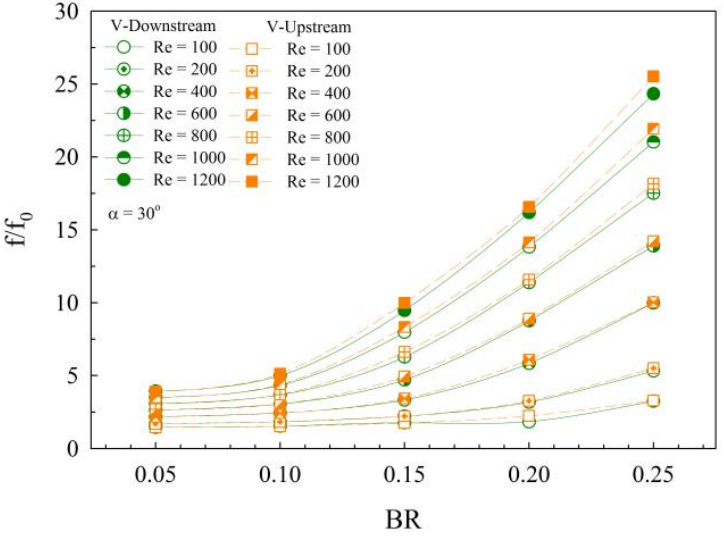

(b)

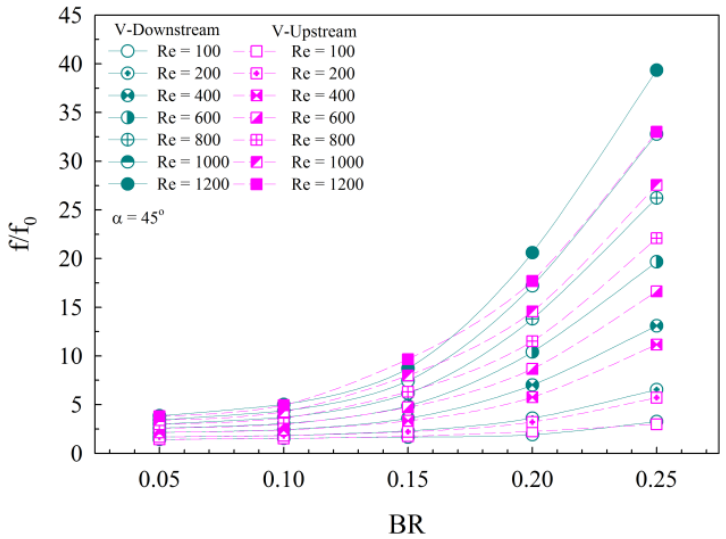

(c)

Fig. 20 f $/ \mathrm{f}_{0}$ versus BR for (a) $\alpha=20^{\circ}$, (b) $30^{\circ}$ and (c) $45^{\circ}$.

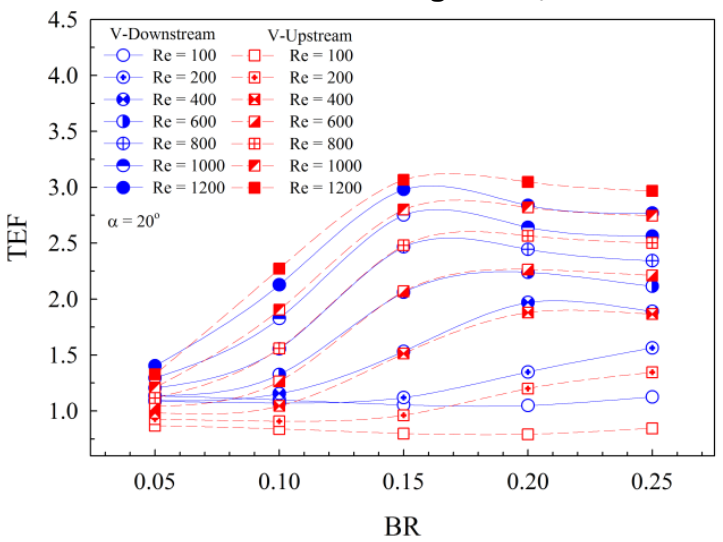

(a)

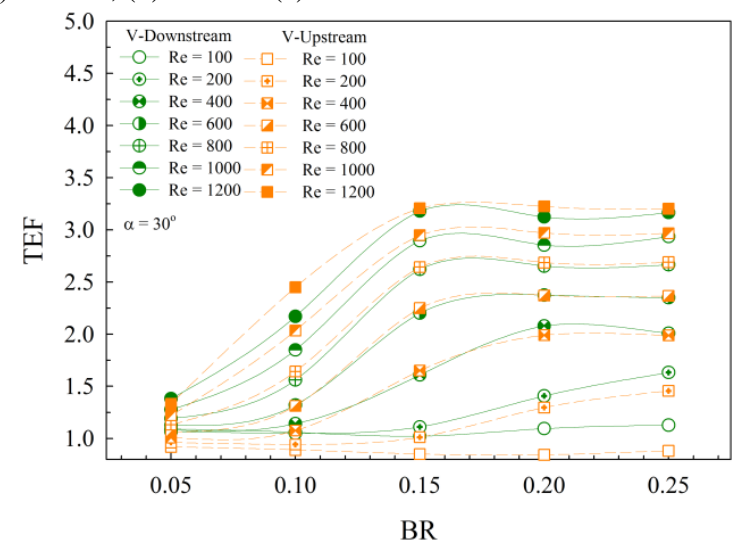

(b)

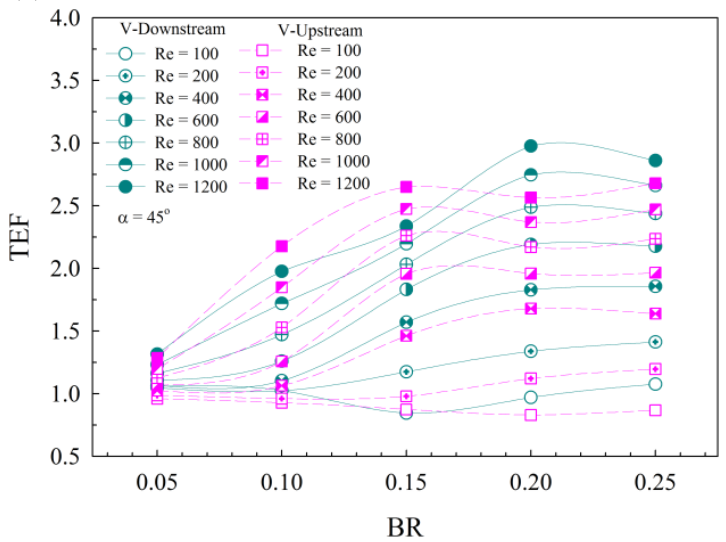

(c)

Fig. $21 \mathrm{TEF}$ versus BR for (a) $\alpha=20^{\circ}$, (b) $30^{\circ}$ and (c) $45^{\circ}$. 


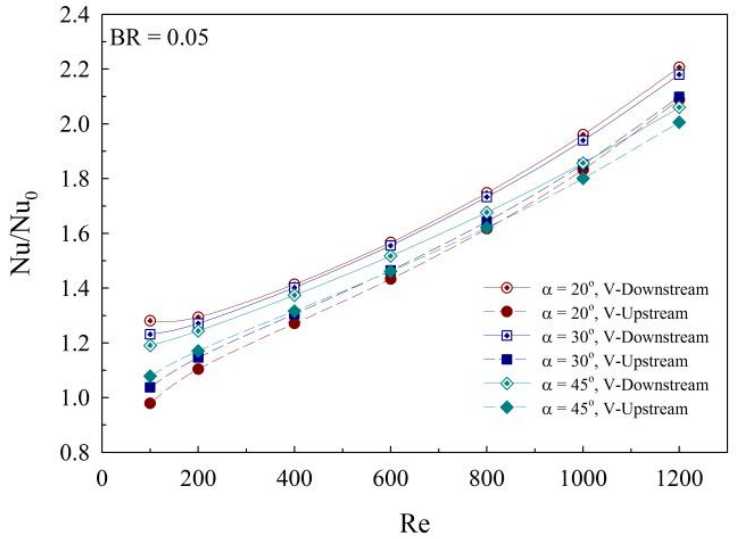

(a)

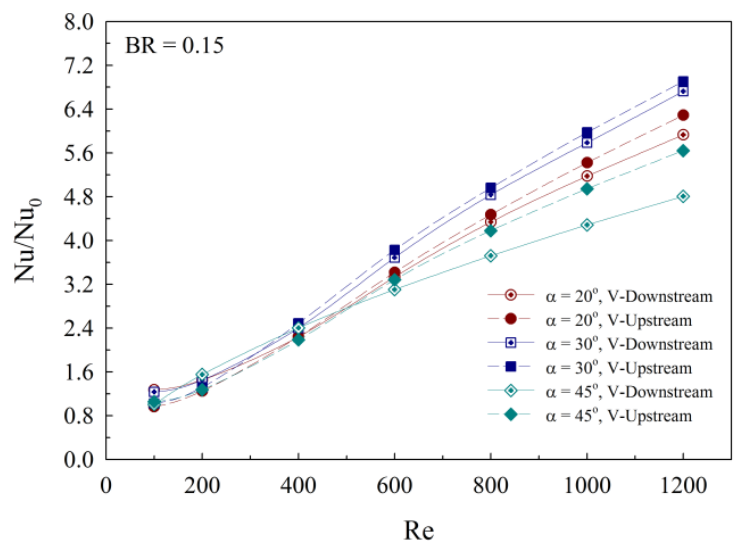

(c)

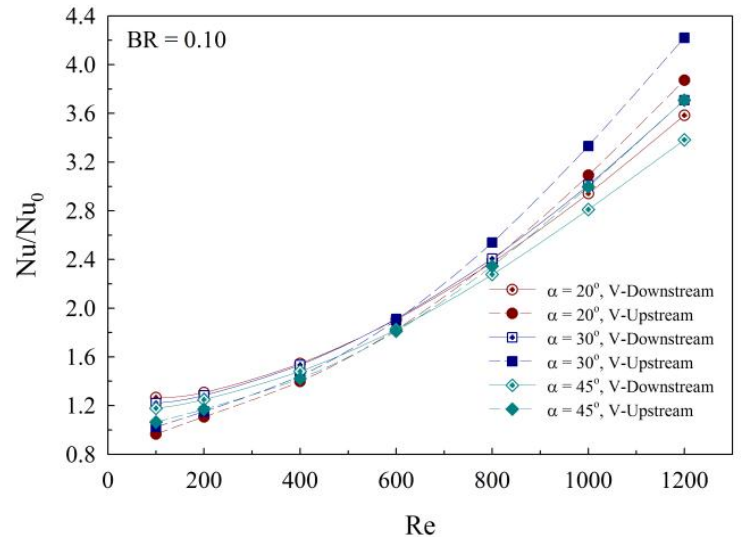

(b)

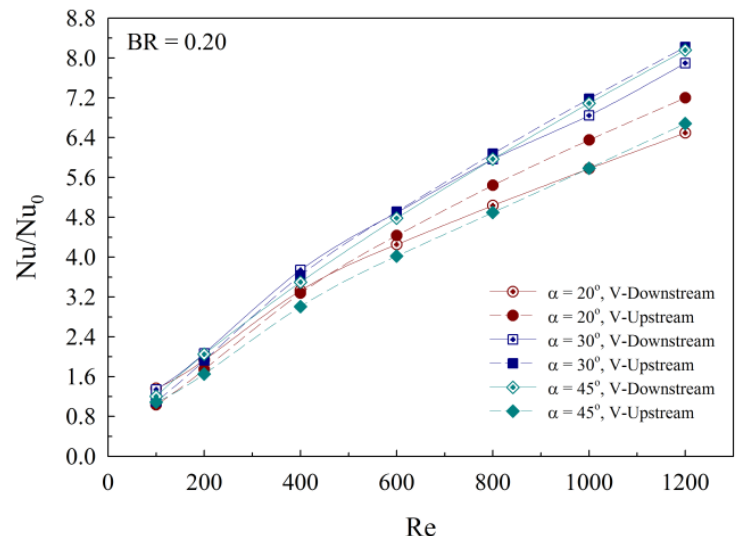

(d)

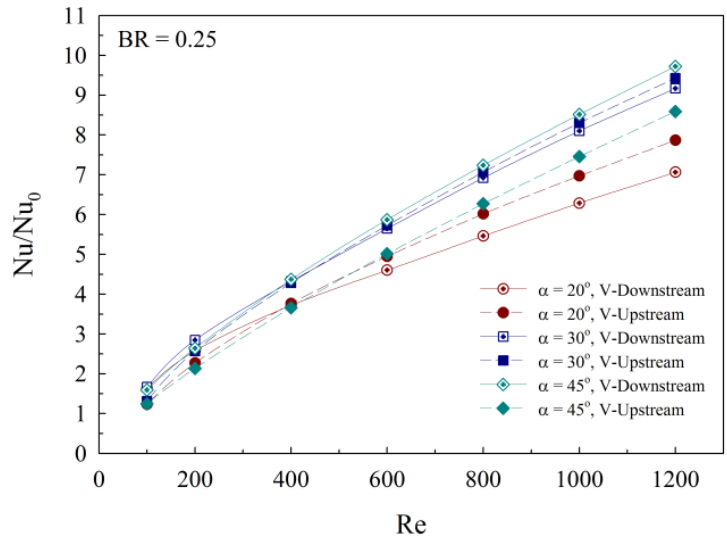

(e)

Fig. $22 \mathrm{Nu} / \mathrm{Nu}_{0}$ versus $\mathrm{Re}$ for (a) $\mathrm{BR}=0.05$, (b) $\mathrm{BR}=0.10$, (c) $\mathrm{BR}=0.15$, (d) $\mathrm{BR}=0.20$ and (e) $\mathrm{BR}=0.25$.

\section{CONCLUSION}

Thermal performance analysis, heat transfer behavior and flow structure in the heat exchanger tube equipped with modified V-shaped baffle are investigated numerically. The influences of Reynolds number, flow attack angle, baffle height and baffle arrangement on heat transfer, pressure loss and thermal performance are considered. As the results, the current investigation can conclude as follows;

The modified $\mathrm{V}$-shaped baffle in the heat exchanger tube produces the vortex flow through the test section. The vortex flow disturbs the thermal boundary layer on the heat transfer surface that is the reason for the heat transfer and thermal performance improvements. The addition of the modified V-shaped baffle not only enhances heat transfer rate, but also increases pressure loss in the heating system.

The enhancement of the heat transfer rate depends on the augmentation of the vortex strength. The increments of the Reynolds number and baffle height result in the increase in the vortex strength. Therefore, the high heat transfer rate is detected in the case of high Reynolds number and blockage ratio.

Considering at $\mathrm{Re}=1200$, the optimum flow attack angle for the modified $\mathrm{V}$-shaped baffle is $30^{\circ}$ when $\mathrm{BR}>0.05$, while the flow attack angle of $20^{\circ}$ performs the best thermal performance for $\mathrm{BR}=0.05$.

The difference of the modified V-shaped baffle arrangement effects for flow and heat transfer behaviors. The reverse direction of the vortex flow is detected when changes the baffle arrangement. The change of the flow structure leads to the change of the heat transfer behavior.

In rang studied, the optimum of the flow attack angle, blockage ratio and arrangement for the modified $\mathrm{V}$-shaped baffle in the heat exchanger tube are $\alpha=30^{\circ}, \mathrm{BR}=0.15-0.20$ and $\mathrm{V}$-Upstream, respectively, when considering at the TEF. 


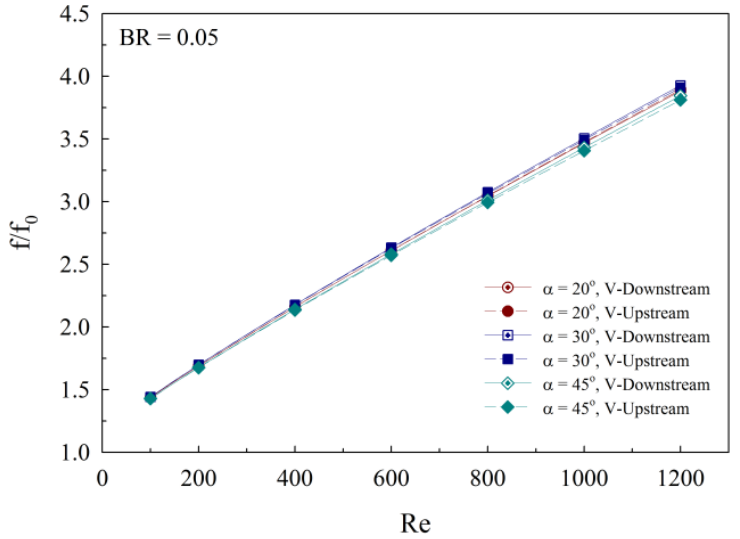

(a)

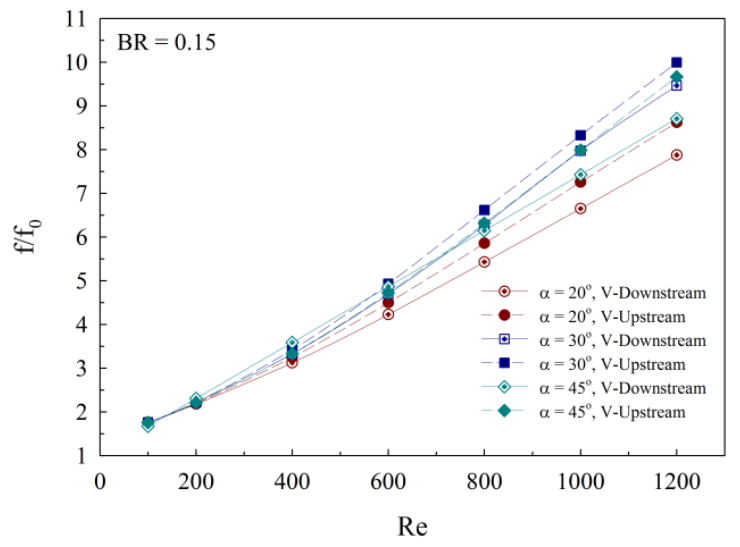

(c)

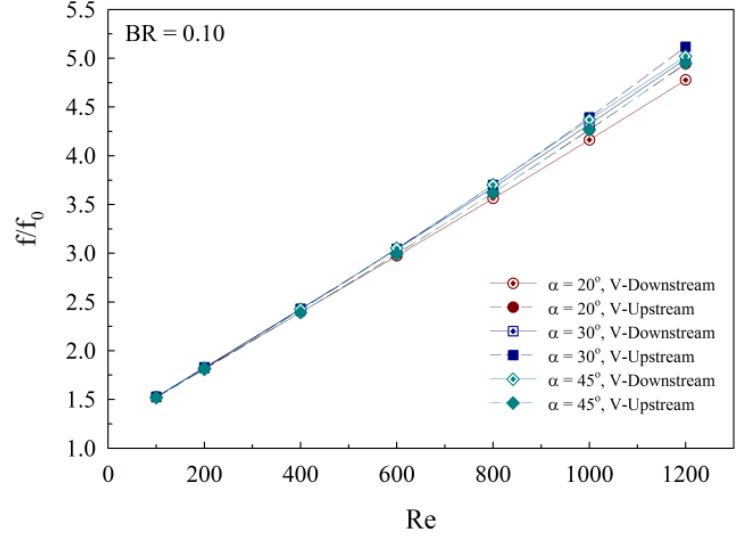

(b)

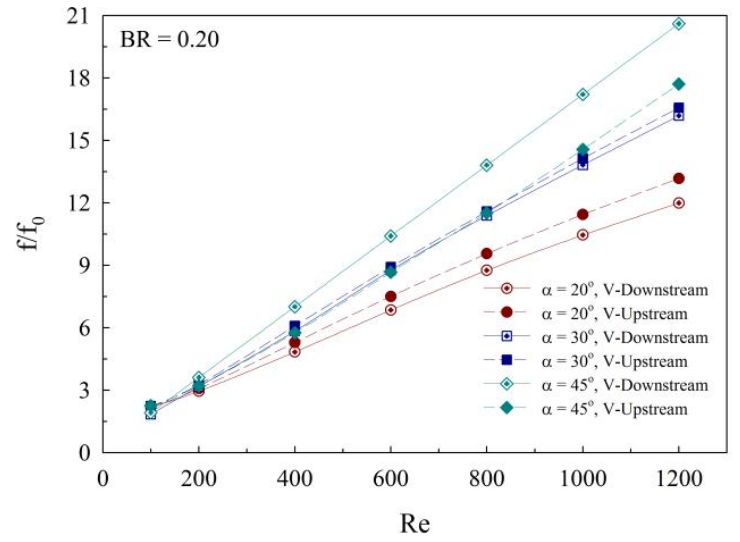

(d)

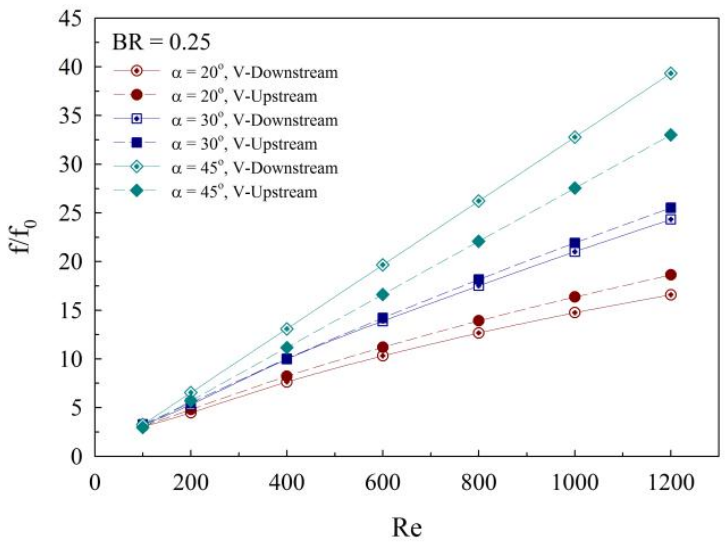

(e)

Fig. $23 \mathrm{f} / \mathrm{f}_{0}$ versus $\mathrm{Re}$ for (a) $\mathrm{BR}=0.05$, (b) $\mathrm{BR}=0.10$, (c) $\mathrm{BR}=0.15$, (d) $\mathrm{BR}=0.20$ and (e) $\mathrm{BR}=0.25$. 


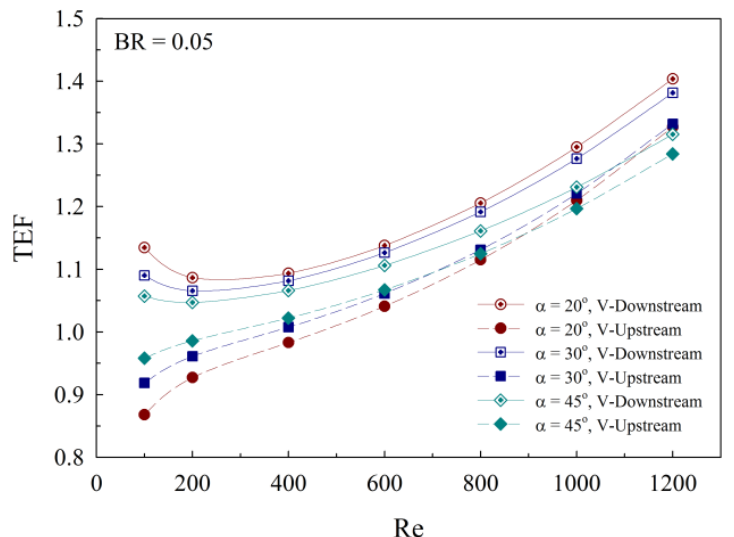

(a)

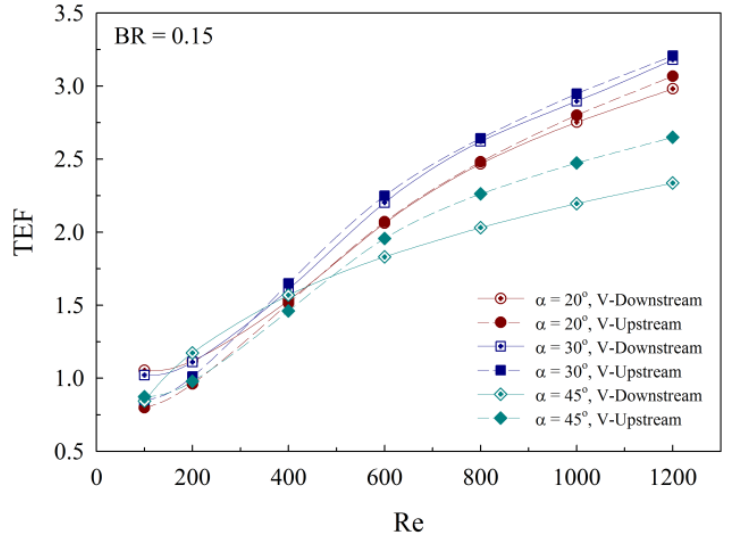

(c)

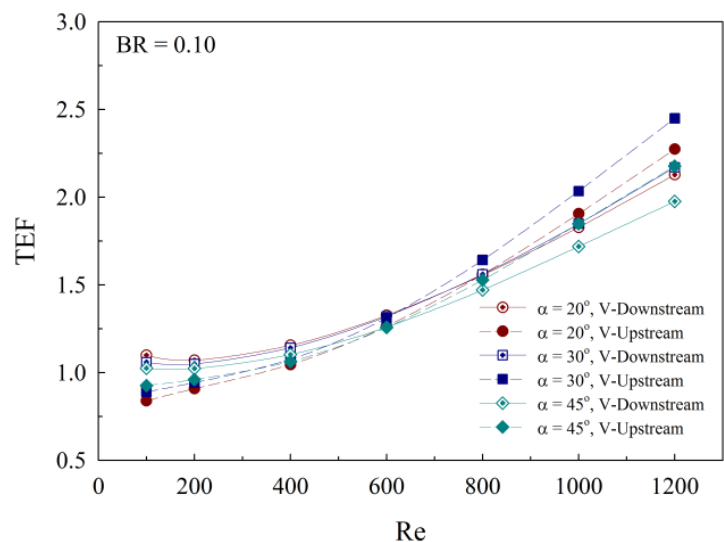

(b)

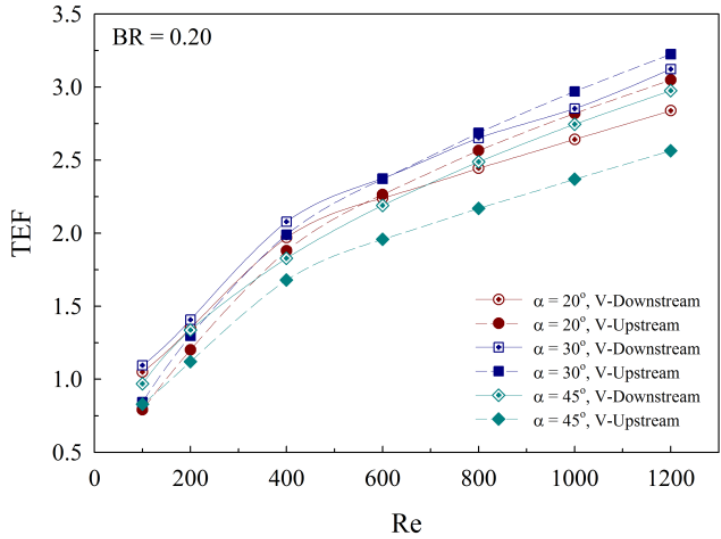

(d)

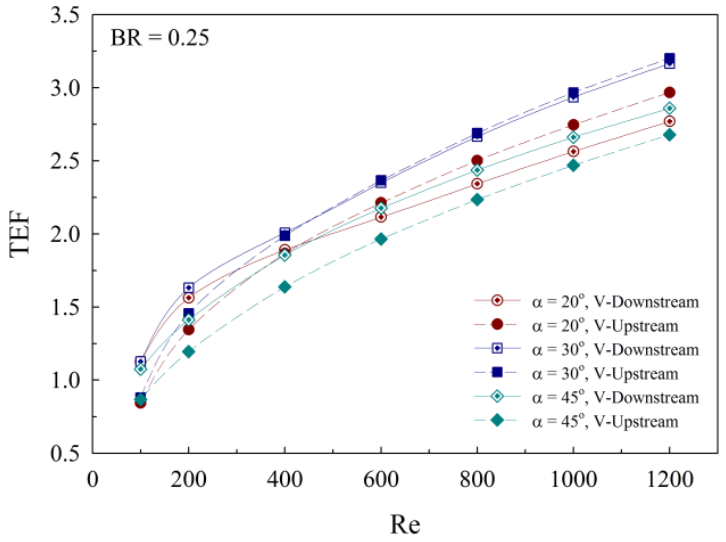

(e)

Fig. 24 TEF versus $R e$ for (a) $B R=0.05$, (b) $B R=0.10$, (c) $B R=0.15$, (d) $B R=0.20$ and (e) $B R=0.25$.

\section{ACKNOWLEDGEMENTS}

The authors would like to acknowledge Assoc. Prof. Dr. Pongjet Promvonge for suggestions. This research was funded by College of Industrial Technology, King Mongkut's University of Technology North Bangkok (Grant No. Res-CIT0218/2018)

\section{NOMENCLATURE}

$B R \quad$ flow blockage ratio $(=b / D)$

$b \quad$ orifice height, $\mathrm{m}$

$D \quad$ diameter of tube

$f \quad$ friction factor

$h \quad$ convective heat transfer coefficient, $\mathrm{W} \mathrm{m}^{-2} \mathrm{~K}^{-1}$

$k$ thermal conductivity, $\mathrm{W} \mathrm{m}^{-1} \mathrm{~K}^{-1}$

$\mathrm{Nu} \quad$ Nusselt number $(=h D / k)$ $p \quad$ static pressure, $\mathrm{Pa}$

$\operatorname{Pr} \quad$ Prandtl number $(P r=0.707)$

Re Reynolds number $(=\rho \bar{u} D / \mu)$

$T$ temperature, $\mathrm{K}$

$u_{i} \quad$ velocity in $x_{i}$-direction, $\mathrm{m} \mathrm{s}^{-1}$

$\bar{u} \quad$ mean velocity in channel, $\mathrm{m} \mathrm{s}^{-1}$

Greek letter

$\alpha \quad$ angle of attack, degree

$T E F \quad$ thermal enhancement factor $\left(=\left(N u / N u_{0}\right) /\left(f / f_{0}\right)^{1 / 3}\right)$

$\rho \quad$ density, $\mathrm{kg} \mathrm{m}^{-3}$

Subscript

in inlet

0 smooth tube

pp pumping power 


\section{REFERENCE}

Abraham, S., and Vedula, R.P., 2016, "Heat Transfer and Pressure Drop Measurements in a Square Cross-section Converging Channel with V and W Rib Turbulators," Experimental Thermal and Fluid Science, 70, 208-219.

https://doi.org/10.1016/j.expthermflusci.2015.09.003

Caliskan, S., and Baskaya, S., 2012, "Velocity Field and Turbulence Effects on Heat Transfer Characteristics from Surfaces with VShaped Ribs," International Journal of Heat and Mass Transfer, 55(2122), 6260-6277.

https://doi.org/10.1016/j.ijheatmasstransfer.2012.06.056

Deo, N.S., Chander, S., and Saini, J.S., 2016, "Performance Analysis of Solar Air Heater Duct Roughened with Multigap V-Down Ribs Combined with Staggered Ribs," Renewable Energy, 91, 484-500.

https://doi.org/10.1016/j.renene.2016.01.067

Fang, X., Yang, Z., Wang, B.C., Tachie, M.F., and Bergstrom, D.J., 2015, "Highly-disturbed Turbulent Flow in a Square Channel with VShaped Ribs on One Wall," International Journal of Heat and Fluid Flow, 56, 182-197.

https://doi.org/10.1016/j.ijheatfluidflow.2015.07.008

Hans, V.S., Saini, R.P., and Saini, J.S., 2010, "Heat Transfer and Friction Factor Correlations for a Solar Air Heater Duct Roughened Artificially with Multiple V-ribs," Solar Energy, 84(6), 898-911.

https://doi.org/10.1016/j.solener.2010.02.004

Jin, D., Zhang, M., Wang, P., and Xu, S., 2015, "Numerical Investigation of Heat Transfer and Fluid Flow in a Solar Air Heater Duct with Multi V-shaped Ribs on the Absorber Plate," Energy, 89, 178-190.

https://doi.org/10.1016/j.energy.2015.07.069

Jin, D., Zuo, J., Quan, S., Xu, S., and Gao, H., 2017, “Thermohydraulic Performance of Solar Air Heater with Staggered Multiple V-shaped Ribs on the Absorber Plate," Energy, 127, 68-77.

https://doi.org/10.1016/j.energy.2017.03.101

Karwa, R., and Chauhan, K., 2010, "Performance Evaluation of Solar Air Heaters having V-down Discrete Rib Roughness on the Absorber Plate," Energy, 35(1), 398-409.

https://doi.org/10.1016/j.energy.2009.10.007

Karwa, R., and Chitoshiya, G., 2013, "Performance Study of Solar Air Heater having V-down Discrete Ribs on Absorber Plate," Energy, 55, 939-955.

https://doi.org/10.1016/j.energy.2013.03.068

Kumar, A., and Kim, M.H., 2015, "Effect of Roughness Width Ratios in Discrete Multi V-rib with Staggered Rib Roughness on Overall Thermal Performance of Solar Air Channel," Solar Energy, 119, 399414.

https://doi.org/10.1016/j.solener.2015.06.030

Kumar, A., Saini, R.P., and Saini, J.S., 2012, "Experimental Investigation on Heat Transfer and Fluid Flow Characteristics of Air Flow in a Rectangular Duct with Multi V-shaped Rib with Gap Roughness on the Heated Plate," Solar Energy, 86(6), 1733-1749. https://doi.org/10.1016/j.solener.2012.03.014
Kumar, A., Saini, R.P., and Saini, J.S., 2013, "Development of Correlations for Nusselt Number and Friction Factor for Solar Air Heater with Roughened Duct having Multi V-shaped with Gap Rib as Artificial Roughness," Renewable Energy, 58, 151-163.

https://doi.org/10.1016/j.renene.2013.03.013

Kumar, A., and Kim, M.H., 2016, "Heat Transfer and Fluid Flow Characteristics in Air Duct with Various V-pattern Rib Roughness on the Heated Plate: A Comparative Study," Energy, 103, 75-85.

https://doi.org/10.1016/j.energy.2016.02.149

Lee, D.H., Rhee, D.H., Kim, K.M., Cho, H.H., and Moon, H.K., 2009, "Detailed Measurement of Heat/mass Transfer with Continuous and Multiple V-shaped Ribs in Rectangular Channel," Energy, 34(11), 1770-1778.

https://doi.org/10.1016/j.energy.2009.07.011

Maithani, R., and Saini, J.S., 2016, "Heat Transfer and Friction Factor Correlations for a Solar Air Heater Duct Roughened Artificially with V-ribs with Symmetrical Gaps," Experimental Thermal and Fluid Science, 70, 220-227.

https://doi.org/10.1016/j.expthermflusci.2015.09.010

Promthaisong, P., Eiamsa-ard, P., Jedsadaratanachai, W., and Eiamsaard, S., 2016, "Turbulent Heat Transfer and Pressure Loss in a Square Channel with Discrete Broken V-rib Turbulators," Journal of Hydrodynamics, Ser. B, 28(2), 275-283. https://doi.org/10.1016/S1001-6058(16)60629-7

Promvonge, P., Changcharoen, W., Kwankaomeng, S., and Thianpong, C., 2011, "Numerical Heat Transfer Study of Turbulent Square-duct Flow through Inline V-shaped Discrete Ribs," International Communications in Heat and Mass Transfer, 38(10), 1392-1399.

https://doi.org/10.1016/j.icheatmasstransfer.2011.07.014

Ravi, R.K., and Saini, R.P., 2016, "Experimental Investigation on Performance of a Double Pass Artificial Roughened Solar Air Heater Duct having Roughness Elements of the Combination of Discrete Multi V Shaped and Staggered Ribs," Energy, 116, 507-516. https://doi.org/10.1016/j.energy.2016.09.138

Singh, P., and Ekkad, S., 2017, "Experimental Study of Heat Transfer Augmentation in a Two-pass Channel Featuring V-shaped Ribs and Cylindrical Dimples," Applied Thermal Engineering, 116, 205-216. https://doi.org/10.1016/j.applthermaleng.2017.01.098

Singh, S., Chander, S., and Saini, J.S., 2012, "Investigations on Thermo-hydraulic Performance due to Flow-attack-angle in VDown Rib with Gap in a Rectangular Duct of Solar Air Heater," Applied Energy, 97, Pages 907-912.

https://doi.org/10.1016/j.apenergy.2011.11.090

Singh, S., Chander, S., and Saini, J.S., 2011, "Heat Transfer and Friction Factor Correlations of Solar Air Heater Ducts Artificially Roughened with Discrete V-down Ribs," Energy, 36(8), 5053-5064. https://doi.org/10.1016/j.energy.2011.05.052

SriHarsha, V., Prabhu, S.V., and Vedula, R.P., 2009, "Influence of Rib Height on the Local Heat Transfer Distribution and Pressure Drop in a Square Channel with $90^{\circ}$ Continuous and $60^{\circ} \mathrm{V}$ broken Ribs," Applied Thermal Engineering, 29(11-12), 2444-2459. https://doi.org/10.1016/j.applthermaleng.2008.12.015 